NASA/TM-1999-209440

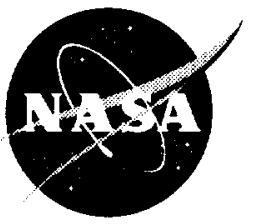

\title{
Rocket-in-a-Duct Performance Analysis
}

Steven J. Schneider and Brian D. Reed

Glenn Research Center, Cleveland, Ohio

Prepared for the

35th Joint Propulsion Conference and Exhibit cosponsored by the AIAA, ASME, SAE, and ASEE

Los Angeles, California, June 20-24, 1999

National Aeronautics and

Space Administration

Glenn Research Center 
Available from

NASA Center for Aerospace Information 7121 Standard Drive

Hanover, MD 21076

Price Code: A03
National Technical Information Service 5285 Port Royal Road Springfield, VA 22100 Price Code: A03 


\title{
ROCKET-IN-A-DUCT PERFORMANCE ANALYSIS
}

\author{
Steven J. Schneider \\ Brian D. Reed \\ National Aeronautics and Space Administration \\ Glenn Research Center \\ Cleveland, Ohio 44135
}

\begin{abstract}
An axisymmetric, $110 \mathrm{~N}$ class, rocket configured with a free expansion between the rocket nozzle and a surrounding duct was tested in an altitude simulation facility. The propellants were gaseous hydrogen and gaseous oxygen and the hardware consisted of a heat sink type copper rocket firing through copper ducts of various diameters and lengths. A secondary flow of nitrogen was introduced at the blind end of the duct to mix with the primary rocket mass flow in the duct. This flow was in the range of 0 to $10 \%$ of the primary massflow and its effect on nozzle performance was measured. The random measurement errors on thrust and massflow were within $+/-1 \%$. One dimensional equilibrium calculations were used to establish the possible theoretical performance of these rocket-in-a-duct nozzles. Although the scale of these tests was small, they simulated the relevant flow expansion physics at a modest experimental cost. Test results indicated that lower performance was obtained at higher free expansion area ratios and longer ducts, while, higher performance was obtained with the addition of secondary flow. There was a discernable peak in specific impulse efficiency at $4 \%$ secondary flow. The small scale of these tests resulted in low performance efficiencies, but prior numerical modeling of larger rocket-in-a-duct engines predicted performance that was comparable to that of optimized rocket nozzles. This remains to be proven in large-scale, rocket-in-a-duct tests.

\section{Introduction}

The rocket-based combined-cycle (RBCC) propulsion system is recognized as a promising technology for Earth-toorbit vehicles $^{1.2}$. These propulsion systems have four modes of operation for the increasing speed regimes of the vehicle. They are: (1) rocket-ejector ramjet, (2) ramjet, (3) scramjet, and (4) rocket-only modes. Many of the advantages of RBCC engines result from certain synergistic benefits that would not occur if the rocket and airbreathing elements operated separately. One of

these benefits is projected to occur in the rocket-only mode of operation at high altitude, when the rocket nozzle flow expands into the engine duct and onto the vehicle afterbody. This flowpath increases the area ratio of the rocket and, therefore, the specific impulse of that mode of operation. This rocket-in-a-duct operation must be considered when optimizing the engine flow path, because a well-designed ramjet or scramjet flow path does not necessarily result in a high efficiency nozzle for the rocket-only mode of operation. Specifically, there are losses in the duct due to the initial
\end{abstract}


shock formation as the rocket plume interacts with the duct and there is viscous dissipation in long ducts.

Recently, a modeling effort ${ }^{3}$ numerically investigated the effect of various parameters on rocket-in-a-duct nozzle performance. These parameters included: rocket exit area ratio $(\varepsilon)$, duct inlet area to rocket throat area ratio, base bleed or secondary flow, duct exit-to-inlet area ratio, and duct length-to-inlet diameter ratio (L/D). Results from this model showed that large free expansion areas at the rocket exit and long ducts decreased performance, while base bleed and larger duct-exit-to-inlet area ratios increased performance. Over the range of parameters investigated, the model predicted nozzle efficiencies from 77 to $95 \%$ of theoretical, one-dimensional equilibrium, vacuum performance.

This paper conducted an experimental assessment of these results using a $110 \mathrm{~N}$ class rocket firing into a duct. The small size of the test articles was expected to lead to increased viscous losses and lower efficiencies in the experimental data as compared to the analytical study. An understanding of the relevant physics of the nozzle flow was the goal of these tests.

\section{Apparatus and Test Procedures}

A sketch of the test configuration is shown in Figure 1. It consisted of a small gaseous hydrogen/gaseous oxygen rocket of area ratio 8 , located inside of a circular duct of diameter, D and length, L. The flow from the rocket nozzle freely expanded to the diameter of the duct and turned to follow the duct. A secondary flow of gaseous nitrogen was injected at the base of the rocket near the blind end of the duct. This secondary flow interacted with the free expansion to establish the pressure at the head end of the duct. This flow was predicted to favorably influence the nozzle performance in Reference 3. The entire assembly was mounted on a thrust stand and performance was measured as outlined below.

Five different rocket-in-a-duct configurations were tested as given in Table 1. These consisted of three different free expansions at a constant length to inlet diameter ratio $(\mathrm{L} / \mathrm{D}=5)$ and three different $L / D$ ratios at a constant free expansion ( $\varepsilon=8$ to 23.5 ). Tests were 4 seconds long to establish steady state pressure at the blind end of the duct. No diverging duct tests were conducted in this series of tests. Secondary flow of gaseous nitrogen, mostly in the range of 0 to $10 \%$ of the core rocket flow, was introduced at the blind end of the duct.

\section{$\underline{\text { Test Articles }}$}

The rocket injector used in this study was designed and fabricated by GenCorp . Aerojet Propulsion Division under contract to NASA Glenn Research Center as part of the Space Station Freedom low thrust, gaseous hydrogen/gaseous oxygen rocket technology program ${ }^{4}$. It was a $110 \mathrm{~N}$ thrust class platelet type injector with inward radial injecton of the propellants. Flame holding was achieved by flow around a bluff body attached to the spark plug tip. The tests were conducted at chamber pressures between 483 and 690 $\mathrm{kPa}$ with a nominal mixture ratio of 4 . The combustion chamber adjacent to the 
injector face was protected with $50 \%$ fuel film cooling which was mixed into the core flow by a secondary combustion trip ring in a water cooled adapter.

The rocket consisted of a heat sink type copper chamber, shown mounted in the baseline rocket test configuration without a duct in Figure 2. The chamber and throat diameters, given in Table 1 , were $2.54 \mathrm{~cm}$ and $1.28 \mathrm{~cm}$, respectively. The rocket had a straight conical nozzle with a $15^{\circ}$ half angle to an area ratio $\varepsilon=8$. Various copper ducts were fabricated from commercial tubing for these tests as shown in Figure 3. Their dimensions are given in Table 1. They were larger in diameter than the rocket and had area ratios of 15.2, 23.5, and 33.4 based on rocket throat area. They were mounted on the large flange shown in Figure 2 for the rocket-in-a-duct tests. An assembly tool was used to ensure concentricity of the duct with the rocket during assembly. One of these assemblies is shown mounted on the injector and watercooled adapter in Figure 4.

\section{Test Facility and Test Procedures}

\section{Overview}

Testing was conducted in Research Combustion Laboratory, Cell 11 (RCL11) at NASA GRC. RCL-11 is a test facility designed for altitude testing of low thrust gaseous hydrogen (GH2)/ gaseous oxygen $(\mathrm{GO} 2)$ rockets. The altitude chamber of this test facility is shown in Figure 5. The altitude chamber was $0.91-\mathrm{m}$ in diameter with viewports for optical access. Mechanical access to the research hardware was provided by a roll-back capability on the tank. A twostage air ejector system provided continuous suction to maintain a $1.4 \mathrm{kPa}$ pressure in the tank. Rockets were mounted horizontally and fired into a water-cooled diffuser shown in Figure 4, during chamber roll-back. The distance between the diffuser and nozzle exit was manually adjusted by means of a bellows joint for different test configurations. The exhaust was cooled by a water spray and vented out through muffler stacks to the atmosphere.

Data acquisition was provided by an autonomous, programmable, digital system. Readings were continuously scanned for out-of-tolerance conditions during testing. Real-time data reduction was performed for mass flowrates and performance parameters. Data storage was provided by floppy disks and, for selected parameters, by strip charts. More detailed information about the facility systems can be found in Reference 5.

\section{Thrust Stand}

The thrust stand is shown in Figure 6. The thrust stand was capable of making steady-state thrust measurements up to $220 \mathrm{~N}$ thrust. The horizontally oriented thrust stand consisted of a mounting plate, a thrust plate, flexures, a 50-lbf measurement load cell, a 50-lbf calibration load cell, and a nitrogenloaded ram for calibration.

The rocket was attached to the thrust stand by the mounting plate. The mounting plate was fabricated from a low thermal conductivity material (bakelite) to minimize thermal variations that could be induced by the rocket. The mounting plate was supported by two lateral restraints or flexures. Three columns connected the mounting plate to 
the thrust plate, which was also supported by two lateral restraints.

Thrust was transmitted from the thrust plate to a load cell. The load cell was not directly connected to the thrust plate, but rather, had a smooth ball at its end, which sat against the thrust plate. This minimized the transmission of side loads to the load cells. A spring-loaded screw was used to maintain contact between the thrust plate and the flexure ball and to preload the measuring load cell. The measuring load cell was aligned axially with the thruster. Pressurized pistons applied a force against the thrust plate to prevent "chattering" of the ball and thrust plate during pressure transients (sea level-to-altitude, altitude-to-sea level) in the tank. The calibration load cell was attached to the ram, whose yoke pushed against the thrust plate during calibration.

Efforts were made to avoid tares on the thrust stand from attachments to the rocket hardware. Propellant lines, water feed lines, and tubing for the pressure transducers were angled into the rocket hardware at $90^{\circ}$ and contributed to flexure stiffness. The pressure transducer tubing was also looped. The ignition cable was contained in thin walled, reinforced Tygon tubing, which was attached to one of the columns on the thrust stand.

In-situ thrust calibrations were performed with pressurized propellant lines and at altitude. Calibration loads were applied by the nitrogen-loaded ram, which pushed against the thrust plate, applying loads on the entire thrust stand. A total of 17 points were taken for each calibration, in roughly equally-spaced increments, going up to approximately 35-lbf simulated thrust, then back down to zero. Typically three thrust calibrations were performed before and after a test series. These calibrations were combined to provide the thrust precision error for that test series. A straight-line fit of the last calibration before testing was used to calculate site thrust. Whenever the test tank was opened, a new set of thrust calibrations was performed.

The nitrogen-loaded ram was also used to apply a simulated load on the thrust stand (approximately $25 \mathrm{lbf}$ ), while data was recorded by the digital data acquisition system, as it would during a real test. This was conducted before and after each test series to determine the data acquisition precision error in thrust (explained further in Appendix A).

\section{Data Reduction}

Ten basic parameters were measured in testing that were used in performance calculations:

$F_{\text {site }}:$ the site force as measured by the thrust stand

$P_{c}:$ chamber static pressure at the injector face

$P_{\text {amb }}$ : the ambient pressure in the altitude chamber

$P_{H 2 . i n}$ : the inlet pressure to the hydrogen critical flow venturi

$T_{H 2, i n}$ : the inlet temperature to the hydrogen critical flow venturi

$P_{\text {O2.in }}$ : the inlet pressure to the oxygen critical flow venturi

$T_{O 2, \text { in }}$ : the inlet temperature to the oxygen critical flow venturi

$P_{N 2 . i n}:$ the inlet pressure to the nitrogen critical flow venturi 
$T_{N 2, \text { in }}:$ the inlet temperature to the nitrogen critical flow venturi

$T_{\text {chimber: }}$ rocket chamber material temperature

From these measured quantities and knowledge of the rocket-in-a-duct geometry, the performance parameters of interest can be determined:

Vacuum Force, $F_{\text {vit }}=F_{\text {site }}+P_{c m b} A_{\text {exit }}$

Vacuum force was determined by free body diagram to be the site force plus the ambient pressure times the nozzle exit area. $A_{\text {exit }}$ is the exit area of the duct. Hydrogen Mass Flowrate,

$m_{H 2}=\left[C_{d} A_{k, i n} \Phi_{i}^{*}\left(\frac{\Phi^{*}}{\Phi_{i}^{*}}\right)\right]_{H 2} \frac{P_{H 2 . i n}}{\sqrt{T_{H 2 . i n}}}$

Oxygen Mass Flowrate, $\dot{m}_{O 2}=\left[C_{d} A_{v e n} \Phi_{i}^{*}\left(\frac{\Phi^{*}}{\Phi_{i}^{*}}\right)\right]_{O 2} \frac{P_{O 2, m}}{\sqrt{T_{O 2, i n}}}$

Nitrogen Mass Flowrate, $m_{N 2}=\left[C_{d} A_{v e n} \Phi_{i}^{*}\left(\frac{\Phi^{*}}{\Phi_{i}^{*}}\right)\right]_{N 2} \frac{P_{N 2 ., n}}{\sqrt{T_{N 2 ., n}}}$

Total Mass Flowrate,

$$
m_{t h t}=m_{H 2}+m_{02}+m_{N 2}
$$

For the mass flowrate calculation, the discharge coefficient $(C d)$, the area of the critical flow orifice or venturi $\left(A_{\text {ren }}\right)$ and two real gas corrections - the ideal sonic flow function $\left(\emptyset_{i}{ }^{*}\right)$ and the ratio of real to ideal sonic flow functions $\left(\emptyset^{*} / \emptyset_{i}{ }^{*}\right)$ were required. $\emptyset_{i}{ }^{*}$ and $\emptyset^{*} / \emptyset_{i}{ }^{*}$ are corrections for real gas effects and are derived in Reference $6 . \emptyset_{i}{ }^{*}$ is strictly a function of the gas properties, while $\emptyset^{*} / \emptyset_{i}^{*}$ is also a function of inlet temperature and pressure. These values have been tabulated for hydrogen, oxygen, and nitrogen in Reference 6 .

Characteristic Velocity,

$$
c^{*}=\frac{P_{t u t} A_{t} g_{c}}{\dot{m_{\omega t}}}
$$

Thrust Coefficient,

$$
C_{t}=\frac{F_{\text {vith }}}{P_{t, t} A_{t}}
$$

Specific Impulse,

$$
I_{s p}=\frac{F_{v a t}}{m_{r i t}}
$$

Note that

$$
I_{s p}={ }^{*} C_{t} / g
$$

Total chamber pressure, $P_{t o t}$, was used in performance calculations. It was related to $P_{c}$, the static pressure measurement made in the injector, behind the combustion zone. The $P_{c}$ measurement was corrected for pressure drop across the combustion zone (due to momentum loss) and then this quantity was converted into stagnation or total pressure using the estimated velocity of the gases in the combustion chamber. The pressure drop across the combustion zone was measured previously in another copper heat sink chamber of the same contour as the one tested in this study.

The rocket throat area, $A_{t}$, was corrected for thermal growth during firing, based on the throat temperature, $T_{\text {chumber }}$, (measured by a thermocouple) and coefficient of thermal expansion of the chamber material, i.e., copper. The constant $g_{c}$ is the gravitational constant. 
Uncertainty Analysis

All measurements have an associated experimental error, where the error is defined as the difference between the measurement and the true value. These errors can be combined to provide the measurement uncertainty for a particular parameter, that is, the maximum error that might reasonably be expected. The uncertainty model for rocket testing recommended in Reference 7 was adopted for this study. The uncertainty analysis methodology is described in Appendix A. Any small bias errors were ignored as negligible in this analysis.

For this study, then, no bias errors were assumed in the uncertainty analysis. The analysis is of random errors only.

The random uncertainty of the measured and calculated parameters was determined for every test firing conducted in this study. There was little variation in the uncertainty values, from test to test. Typical measurement uncertainty values are listed in Table 2 .

The measurement uncertainties were generally around $1 \%$ or less for all of the parameters of interest. A low uncertainty in vacuum thrust was achieved in particular, due to the fact that careful attention was paid to the thrust measurement. There were generally six thrust calibrations and two thrust data acquisition error tests conducted for every test series, which increased the sample size (degrees of freedom) and reduced the measurement uncertainty.

\section{$\underline{\text { Results and Discussion }}$}

The experimental rocket performance parameters defined above, i.e., specific impulse $\left(I_{s p}\right)$, thrust coefficient $\left(C_{f}\right)$, and characteristic velocity $\left(\mathrm{c}^{*}\right)$ were normalized to their theoretical onedimensional equilibrium ${ }^{8}$ values at the measured rocket chamber total pressure, $P_{t o t}$, and inlet flow composition, including secondary nitrogen flow. The one-dimensional equilibrium ${ }^{8}$ program is an industry standard computer program, which assumes that thermodynamic variations occur in only one direction, i.e., parallel to the rocket axis. Equilibrium, at each axial position, is that composition such that the free energy is minimized. This composition results in the theoretical maximum performance for the given rocket chamber total pressure and reference enthalpy of the inlet flow composition. The normalized performance parameters are defined as follows:

$$
\begin{aligned}
& \eta_{I_{y *}}=\left[I_{s p} / I_{s p O D E}\right]_{v a t} \\
& \eta_{C,}=\left[C_{f} / C_{\text {YODE }}\right]_{\text {var }} \\
& \eta_{c^{*}}=c^{*} / c^{*}
\end{aligned}
$$

where the subscripts $v a c$ - based on vacuum thrust $O D E$ - based on one-dimensional equilibrium 
Values of $\eta_{\text {Isp. }} \eta_{C^{*}}$ and $\eta_{C r}$ are given in Table 3 for relevant numerical cases computed in Reference 3 . The value of $\eta_{\text {Isp }}$ was given in the Reference 3 . The value of $\eta_{C^{*}}$ was assumed to be 1.0 in the Reference 3 , but, by the definitions used in this paper, the secondary flow must be included and $\eta_{\mathrm{C}}$ was reduced to 0.926 for $8 \%$ secondary flow. This secondary flow had the effect of lowering the experimental characteristic velocity, $c^{*}$, of the rocket chamber, since it did not flow through the rocket throat and thereby, contribute to the chamber pressure, $P_{t, t}$. The injection of secondary flow, therefore, was counted as a loss of $\mathrm{c}^{*}$ in this paper. The secondary flow interacted with the rocket flow as it flowed through the duct nozzle and influenced in the nozzle thrust coefficient. By definition, thrust coefficient efficiency, $\eta_{\mathrm{Cf}}$, was calculated by the following equation:

$\eta_{c,}=\eta_{L \mathrm{sp}} / \eta_{\mathrm{c}^{*}}$

The predicted specific impulse efficiency, thrust coefficient efficiency, and characteristic velocity efficiency, given in Table 3, are shown in Figure 7, 8 , and 9 , respectively, as a function of secondary flow for three different free expansions at $\mathrm{L} / \mathrm{D}=5$. Note the decrease in $\eta_{\text {Isp }}$ and $\eta_{c f}$ as the free expansion percent increases and the increase in $\eta_{\mathrm{lsp}}$ and $\eta_{C f}$ as secondary flow increases. The $\eta_{C^{*}}$ decreases with the addition of secondary flow as discussed above. Note that the increase in $\eta_{\mathrm{Cf}}$ and the decrease in $\eta_{C} *$ with the addition of secondary flow had canceling effects in $\eta_{\text {ssp }}$, but a slight increase was still predicted.

The experimental data for each test run for this paper is given in Appexdix B.
Data for the baseline rocket and the five rocket-in-a-duct configurations was included. The theoretical onedimensional equilibrium ${ }^{8}$ performance was calculated at $P_{t \prime \prime}$ and at the experimentally measured mixture ratio, including gaseous nitrogen diluent.

The measured head end pressure, $P_{\text {head }}$, at the blind end of the duct for each test run was normalized to the rocket chamber total pressure and plotted in Figure 10 as a function of secondary flow for the five rocket-in-a-duct configurations tested. The curves are linear regression curve fits to aid in viewing the data. One notes that, for these tests, head end pressures are in the range of 0.2 to $1.3 \%$ of the rocket chamber pressure and that head end pressure rises with the addition of secondary flow. One also notes that larger free expansion area ratios result in lower head end pressures. There was also no discernable effect of duct length on head end pressure. These measurements indicated that head end pressure was controlled by the pressure in the free expansion zone and not by downstream pressure. A test at higher downstream pressure was conducted to verify that downstream pressure was not communicated to the pressure at the head end of the duct.

The measured specific impulse efficiency, $\eta_{\text {Isp }}$, thrust coefficient efficiency, $\eta_{C f}$, and characteristic velocity efficiency, $\eta_{C^{*}}$, given in Tables B2, B3, and B6, for three different free expansions at $\mathrm{L} / \mathrm{D}=5$ are shown in Figures 11, 12, and 13, respectively, as a function of secondary flow. The baseline rocket data given in Table $\mathrm{B} 1$ was plotted for reference. Note that there was 
undesirable scatter in $\eta_{C^{*}}$ shown in Figure 13. Ideally, this data would collapse to a single line as shown in Figure 9 for the numerical data. This scatter indicated that the performance of the injector could be sensitive to mixture ratio and chamber pressure, which influence the gaseous propellant massflows and their injection velocities. Also, the integrity of the seals could be different for each test setup, resulting in day-to-day variations in $\eta_{C^{*}}$. This could explain why the baseline rocket performance is higher than the other data in Figure 13.

Note that, as with the numerical results, there was a decrease in $\eta_{\mathrm{Cr}}$ as the free expansion percent increases and the increase in $\eta_{c f}$ as secondary flow increases shown in Figure 12. The $\eta_{C *}$ decreased with the addition of secondary flow as discussed previously and had the undesirable scatter discussed above. Note, again that the increase in $\eta_{C f}$ and the decrease in $\eta_{C^{*}}$ with the addition of secondary flow had canceling effects in $\eta_{\text {Isp }}$, but there was a discernable peak in $\eta_{\text {Isp }}$ at $4 \%$ secondary flow shown in Figure 11.

The measured specific impulse efficiency, $\eta_{\text {Isp }}$, thrust coefficient efficiency, $\eta_{\mathrm{Cf}}$, and characteristic velocity efficiency, $\eta_{C^{*}}$, given in Tables B2, B4, and B5, for three different nozzle lengths are shown in Figures 14, 15 , and 16 , respectively, as a function of secondary flow. The baseline rocket data given in Table Bl was plotted for reference. Note again that there was undesirable scatter in $\eta_{\mathrm{C}^{*}}$ shown in Figure 16 and that $\eta_{C *}$ for the 3 diameter long duct had a low bias. Ideally, this data would collapse to a single line as shown in Figure 9 for the numerical data. Again, the baseline rocket performance is higher than the other data in Figure 16.

Note that there was a decrease in $\eta_{C f}$ as the length of the duct increases and the increase in $\eta_{\mathrm{Cf}}$ as secondary flow increases as shown in Figure 15. The $\eta_{C^{*}}$ decreased with the addition of secondary flow as discussed previously and had the undesirable scatter discussed above. Note, again that the increase in $\eta_{\mathrm{Cr}}$ and the decrease in $\eta_{C^{*}}$ with the addition of secondary flow had canceling effects in $\eta_{\text {Isp }}$, but there was a discernable peak in $\eta_{\text {Isp }}$ at $4 \%$ secondary flow shown in Figure 14.

Finally, note that the computational data of Reference 3 predicted that larger nozzles have higher efficiencies than the small-scale ducts reported in this paper. In fact, performance of the rocket-in-aduct with secondary flow was predicted to be comparable to that of other optimized rocket nozzles. Higher performance of larger nozzles can be anticipated due to the lower viscous losses, but this remains to be proven in a large-scale, rocket-in-a-duct.

\section{Summary}

An understanding of the relevant physics of rocket-in-a-duct flows was experimentally tested in a $110 \mathrm{~N}$ class, gaseous hydrogen, gaseous oxygen, rocket altitude test facility. Copper heat sink type test apparatus was employed and industry standard rocket test procedures and uncertainty analyses were used. These tests simulated the relevant flow expansion physics and were economical to run. Facility thrust 
random measurement error was within $+/-1 \%$. Five different rocket-in-a-duct configurations were tested with a secondary flow of gaseous nitrogen introduced at the blind end of the duct. The experimental specific impulse efficiency, $\eta_{\text {lsp }}$, thrust coefficient efficiency, $\eta_{\mathrm{Cf}}$, and characteristic velocity efficiency, $\eta_{C^{*}}$ for three different free expansions at $\mathrm{L} / \mathrm{D}=5$ and three different duct lengths with a free expansion between $\varepsilon=8$ to 23.5 were given as a function of secondary flow. There was undesirable scatter in $\eta_{C^{*}}$ which could be injector and/or seal related. There was a decrease in $\eta_{\mathrm{Cf}}$ as the free expansion percent increased and as the length of the duct increased. An increase in $\eta_{C f}$ occurred as secondary flow increased. The $\eta_{C^{*}}$ decreased with the addition of secondary flow by definition. The increase in $\eta_{\mathrm{Cf}}$ and the decrease in $\eta_{C^{*}}$ with the addition of secondary flow had canceling effects in $\eta_{\text {lsp }}$, but there was a discernable peak in $\eta_{\text {Isp }}$ at $4 \%$ secondary flow. Prior numerical modeling of larger rocket-ina-duct engines predicted possible nozzle performance comparable to that of other optimized rocket nozzles, but this remains to be proven in a large-scale, rocket-in-a-duct.

\section{References}

1. Daines, R. and Segal, C., "Combined Rocket and Airbreathing Systems for Space Launch Applications", Journal of Propulsion and Power, Vol. 14, No. 5, pp 605-612. September-October 1998

2. Trefny, C., "An Air-Breathing Launch Vehicle Concept for Single-Stage-to-Orbit", AIAA 99-2730, $35^{\text {th }}$ AIAA/ASME/SAE/ASEE Joint Propulsion Conference, Los Angeles, June 1999

3. Steffen, C. J., Smith, T. D., Yungster, S., and Keller, D. J., "Rocket Based CombinedCycle Analysis Using NPARC", AIAA 98-0954, $36^{\text {th }}$ Aerospace Sciences Meeting, Reno, January 1998

4. Robinson, P. J., "Space Station Auxiliary Thrust Chamber Technology", NASA CR185296, July 1990

5. Arrington, L. A. and Schneider, S. J., "Low Thrust Rocket Test Facility", AIAA 90$2503,26^{\text {th }}$ AIAA/ASME/SAE/ASEE Joint Propulsion Conference, Orlando, July 1990

6. "Fluid Meters: Their Theory and Application", American Society of Mechanical Engineers, 1971

7. "Handbook for Estimating the Uncertainty in Measurements Made with Liquid Propellant Rocket Engine Systems", CPIA 180, Chemical Propulsion Information Agency, April 1969

8. McBride, B. and Gordon, S., "Computer Program for Calculation of Complex Chemical Equilibrium Compositions and Applications", NASA RP-1311, June 1996 


\begin{tabular}{|c|c|c|c|c|c|c|c|c|}
\hline \multicolumn{2}{|c|}{ Combustion Chamber } & Throat & Nozzle & \multicolumn{4}{c|}{ Duct } \\
\hline length cm & diameter cm & diameter $\mathbf{c m}$ & $\boldsymbol{\varepsilon}$ & L cm & D cm & $\boldsymbol{\varepsilon}$ & \%£ free & L/D \\
\hline 5.08 & 2.54 & 1.278 & 8 & 24.88 & 4.976 & 15.2 & 47.4 & 5 \\
\hline 5.08 & 2.54 & 1.278 & 8 & 18.55 & 6.185 & 23.5 & 66 & 3 \\
\hline 5.08 & 2.54 & 1.278 & 8 & 30.92 & 6.185 & 23.5 & 66 & 5 \\
\hline 5.08 & 2.54 & 1.278 & 8 & 43.29 & 6.185 & 23.5 & 66 & 7 \\
\hline 5.08 & 2.54 & 1.278 & 8 & 36.92 & 7.384 & 33.4 & 76 & 5 \\
\hline
\end{tabular}

Table 1. Rocket-in-a-duct configurations tested.

\begin{tabular}{|c|c|}
\hline Parameter & Measurement Uncertainty (\%) \\
\hline Total Chamber Pressure & 0.57 \\
\hline Vacuum Force & 0.47 \\
\hline Oxygen Mass Flowrate & 1.07 \\
\hline Hydrogen Mass Flowrate & 1.01 \\
\hline Nitrogen Mass Flowrate & 1.00 \\
\hline Total Mass Flowrate & 0.44 \\
\hline Mixture Ratio & 1.43 \\
\hline Characteristic Velocity & 1.04 \\
\hline Thrust Coefficient & 0.73 \\
\hline Specific Impulse & 0.95 \\
\hline
\end{tabular}

Table 2. Typical Measurement Uncertainty Values

\begin{tabular}{|c|c|c|c|c|c|c|c|}
\hline Case & $P \boldsymbol{C} \sim$ Mpa & Sec. Flow \% & Free Exp $\varepsilon$ & $\% \varepsilon$ Free & $\eta$ Isp & $\eta \mathbf{C}^{*}$ & $\eta$ Cf \\
\hline 4 & 2.1 & 0 & $4-200$ & 0.98 & 0.778 & 1.000 & 0.778 \\
\hline 12 & 8.3 & 0 & $4-200$ & 0.98 & 0.797 & 1.000 & 0.797 \\
\hline 15 & 8.3 & 8 & $20-200$ & 0.90 & 0.880 & 0.926 & 0.951 \\
\hline 19 & 2.1 & 0 & $20-200$ & 0.90 & 0.867 & 1.000 & 0.867 \\
\hline 20 & 2.1 & 8 & $4-200$ & 0.98 & 0.800 & 0.926 & 0.864 \\
\hline 35 & 8.3 & 8 & $20-39$ & 0.49 & 0.901 & 0.926 & 0.973 \\
\hline
\end{tabular}

Table 3. Computational results for rocket-in-a-duct, $L / D=5$, constant area. (Reference 3) 


\section{Appendix A: Uncertainty Analysis Methodology}

Every measurement and every parameter calculated from measurements have an associated uncertainty value. Reference 7 has a recommended methodology for determining the measurement uncertainty in rocket testing. This methodology was adopted for the testing conducted in this study and is described below.

The measured parameters in this study for which there is an associated error are summarized in Table Al. The sources of error for each parameter can be divided into three categories: calibration errors, data acquisition errors, and data reduction errors. Each of these elemental sources of errors can have two components, a precision (random) error and a bias (fixed) error associated with it.

The bias error is a constant, systematic deviation from the true value. The calibration of the measuring instruments was used to eliminate large known biases. Control of the measuring process was used to insure that there were no large unknown bias errors (such as thermal drift). Any small bias errors were ignored as negligible in this analysis. For this study, then, no bias errors were assumed in the uncertainty analysis. The analysis is of random errors only.

The precision error is the variation seen in repeated measurements and is characterized by the precision error index, $(s)$. The precision index for a set of repeated measurements is defined by:

$$
s=\sqrt{\frac{\sum_{i=1}^{N}\left(x_{i}-\bar{x}\right)^{2}}{N-1}}
$$

where $N=$ number of measurements made, $x_{i}=$ the individual measurements, and $\bar{x}=$ the average value of the individual measurements.

The sample size or the number of degrees of freedom ( $d f)$ associated with the above precision index is defined as

$$
d f=N-1
$$

The calibration precision errors in the measuring instruments were determined through offline calibration (sonic venturis), in-situ calibration (load cell), or manufacturers' specifications (pressure transducers, thermocouples). For geometric parameters (throat and nozzle areas), the precision error was estimated as the square of the specified diameter tolerance. For the sonic flow function ratios, which were estimated from curve fits of table data, precision error was determined from the Standard Estimate of Error $\left(S_{E E}\right)$,

$S_{E E}=\sqrt{\frac{\sum_{i=1}^{N}\left(y_{i}-y_{i .}\right)^{2}}{N-C}}$

where $y_{i}=$ the data point, $y_{i, c}=$ the equivalent calculated value from the curve fit, $\mathrm{N}=$ number of data points, and $\mathrm{C}=$ number constants used in the curve fit.

Here the number of degrees of freedom was defined as 
$d f=N-C$.

Data acquisition errors are those associated with the output signal from the measuring instrument to the recording device. Sources of errors here include the excitation voltage, signal conditioning, and signal gain. In this study, data acquisition errors were determined by end-to-end calibrations (load cell) or from the manufacturer's calibration data on the data acquisition cards (pressure transducers and thermocouples). The data reduction errors are those due to computer resolution and, for this study, were assumed to be zero.

The elemental sources of error for the measured parameters were combined using the root sum square. So the calibration precision errors $\left(S_{(c)}\right)$ and data acquisition precision errors $\left(S_{d t}\right)$ were be combined such that for a measuring instrument, $\mathrm{Mi}$,

$$
S_{M i}=\sqrt{S_{c a t}^{2}+S_{d a}^{2}}
$$

The number of degrees of freedom was defined as,

$$
d f_{M i}=\frac{\left[S_{c u t}^{2}+S_{d u}^{2}\right]^{p}}{\frac{S_{c u l}^{4}}{d f_{c a l}}+\frac{S_{d u}^{4}}{d f_{d u}}}
$$

Performance parameters, such as specific impulse, thrust coefficient, and characteristic velocity were calculated from the measured parameters. Parameters such as vacuum force and mass flowrate are determined from measured parameters. The calculated parameters used in this study are summarized in Table A2.
It was necessary to propagate the errors in the measured parameters to calculated parameters. The error propagation was approximated with Taylor's series methods. Assume that the performance parameter, $P j$, is calculated from $\mathrm{N}$ measured parameters such that,

$$
P j=f\left(M_{1}, \ldots, M_{i}, \ldots, M_{N}\right)
$$

Then the precision error for $P j$ was calculated from the precision errors of the measured parameters from

$$
S_{P j}=\sqrt{\sum_{i=1}^{N}\left[\left(\frac{\partial P_{j}}{\partial M_{i}}\right)\left(S_{M_{i}}\right)\right]^{2}}
$$

The number of degrees of freedom for $P j$ can determined from

$$
d f_{P j}=\frac{\left[\sum_{i=1}^{N}\left[\left(\frac{\partial P_{j}}{\partial M_{i}}\right)\left(S_{M_{i}}\right)\right]^{2}\right]^{2}}{\sum_{i=1}^{N}\left[\frac{\left.\left(\frac{\partial P_{j}}{\partial M_{i}}\right)\left(S_{M i}\right)\right]^{+}}{d f_{M i}}\right]}
$$

The partial derivative, $\delta P j / \delta M i$, is called the influence coefficient and is the first term in a Taylor's series expansion. So, the partial derivative of the performance parameter with respect to each measurement in the performance equation must be found for error propagation. Propagation must be done with every parameter for which an error might exist. That is, the error of every calculated parameter in Table A2 must be related back to the error of every appropriate measured parameter in Table A1. For example, the influence of the precision error in the hydrogen inlet pressure measurement (used for hydrogen mass flowrate) on the specific 
impulse error would be determined by the derivative of the specific impulse equation with respect to the hydrogen inlet pressure (imbedded in the total mass flowrate parameter).

The value for measurement uncertainty for the performance parameter $P j$, used to express a reasonable limit for error was defined in Reference 7 as,

$U_{P j}= \pm\left(B_{P_{j}}+t_{95 . d f_{p_{j}}} S_{P_{j}}\right)$

where $S_{P j}=$ precision error, $B_{P j}=$ bias error, and $t_{9.5}=$ Students number, the 95th percentile point for the two-tailed Students " $t$ " distribution. The measurement uncertainty, $U_{P_{j}}$, was a statistical band within which the true value of the measured parameter was expected to lie, at a $95 \%$ confidence level. In this analysis, the bias error is zero.

The Students number was used to inflate the value of $U_{P_{j}}$ to reduce the risk of underestimating $S_{P_{j}}$ when a small sample was used to calculate $S_{P_{j}}$. The $t_{95} d f_{P_{j}}$ value was a function of the size of the sample (the number of degrees of freedom, $d f_{P_{j}}$ ) used in calculating $S_{P_{j}}$. For small sample sizes $t_{95} d f_{P j}$ will be large, while for larger samples $t_{95} d f_{P_{j}}$ will be smaller. The value of $t_{95, \infty}=1.96$ for an infinite number of degrees of freedom and $t_{95.30}=2.04$ at 30 degrees of freedom, so a value of 2.0 was assumed for $t_{9,5}$ is used for $d f=30$ or above.

\begin{tabular}{|l|}
\hline \multicolumn{1}{|c|}{ Measured Parameters } \\
\hline Chamber Pressure \\
\hline Ambient Pressure \\
\hline Site Force \\
\hline Rocket Throat Area \\
\hline Rocket Nozzle Exit Area \\
\hline Hydrogen Venturi Discharge Coefficient \\
\hline Hydrogen Venturi Sonic Flow Function Ratio \\
\hline Hydrogen Venturi Throat Area \\
\hline Hydrogen Venturi Inlet Pressure \\
\hline Hydrogen Venturi Inlet Temperature \\
\hline Oxygen Venturi Discharge Coefficient \\
\hline Oxygen Venturi Sonic Flow Function Ratio \\
\hline Oxygen Venturi Throat Area \\
\hline Oxygen Venturi Inlet Pressure \\
\hline Oxygen Venturi Inlet Temperature \\
\hline Nitrogen Venturi Discharge Coefficient \\
\hline Nitrogen Venturi Sonic Flow Function Ratio \\
\hline Nitrogen Venturi Throat Area \\
\hline Nitrogen Venturi Inlet Pressure \\
\hline Nitrogen Venturi Inlet Temperature \\
\hline
\end{tabular}

Table A1: Measured Parameters 


\begin{tabular}{|l|}
\hline \multicolumn{1}{|c|}{ Calculated Parameters } \\
\hline Total Chamber Pressure \\
\hline Hydrogen Mass Flowrate \\
\hline Oxygen Mass Flowrate \\
\hline Nitrogen Mass Flowrate \\
\hline Total Mass Flowrate \\
\hline Mixture Ratio \\
\hline Vacuum Force \\
\hline Characteristic Velocity \\
\hline Thrust Coefficient \\
\hline Specific Impulse \\
\hline
\end{tabular}

Table A2: Calculated Parameters 


\section{Appendix B. Experimental Data}

\begin{tabular}{|c|c|c|c|c|c|c|c|c|c|c|c|c|}
\hline Ptot(kPa) & MR & $\%$ N2 & Isp(sec) & $\mathrm{c}^{*}(\mathrm{~m} / \mathrm{sec})$ & $\mathrm{Cf}$ & Fvac(N) & mtot $(g / s)$ & Isp-eff & $c^{\star}$ eff & Cteff & Phead(kPa) & Pamb(kPa) \\
\hline 462.3 & 3.66 & N/A & 342 & 2297 & 1.462 & 86.6 & 25.8 & 0.784 & 0.914 & 0.858 & $\mathrm{~N} / \mathrm{A}$ & 1.69 \\
\hline 462.3 & 3.96 & $\mathrm{~N} / \mathrm{A}$ & 341 & 2287 & 1.464 & 87.4 & 26.1 & 0.785 & 0.919 & 0.855 & $\mathrm{~N} / \mathrm{A}$ & 1.58 \\
\hline 469.2 & 3.87 & $\mathrm{~N} / \mathrm{A}$ & 342 & 2301 & 1.456 & 88.2 & 26.3 & 0.786 & 0.922 & 0.852 & N/A & 1.61 \\
\hline 483.0 & 3.89 & N/A & 339 & 2283 & 1.457 & 90.8 & 27.3 & 0.779 & 0.915 & 0.852 & $\mathrm{~N} / \mathrm{A}$ & 1.61 \\
\hline 496.8 & 3.82 & $\mathrm{~N} / \mathrm{A}$ & 346 & 2335 & 1.454 & 93.0 & 27.4 & 0.795 & 0.934 & 0.851 & N/A & 1.68 \\
\hline 517.5 & 3.81 & N/A & 348 & 2350 & 1.452 & 96.0 & 28.1 & 0.799 & 0.939 & 0.851 & N/A & 1.75 \\
\hline 552.0 & 4.01 & $\mathrm{~N} / \mathrm{A}$ & 339 & 2295 & 1.450 & 102.3 & 30.7 & 0.781 & 0.923 & 0.846 & N/A & 1.68 \\
\hline 558.9 & 3.97 & $\mathrm{~N} / \mathrm{A}$ & $\overline{346}$ & 2345 & 1.449 & 104.2 & 30.7 & 0.796 & 0.942 & 0.846 & N/A & 1.77 \\
\hline 565.8 & 3.94 & $\mathrm{~N} / \mathrm{A}$ & 345 & 2331 & 1.450 & 105.4 & 31.2 & 0.793 & 0.935 & 0.847 & N/A & 1.84 \\
\hline 655.5 & 3.91 & $N / A$ & 342 & 2332 & 1.437 & 121.0 & 36.1 & 0.786 & 0.934 & 0.841 & N/A & 1.80 \\
\hline 662.4 & 4.03 & $\mathrm{~N} / \mathrm{A}$ & 341 & 2314 & 1.443 & 122.8 & 36.7 & 0.785 & 0.930 & 0.842 & $\mathrm{~N} / \mathrm{A}$ & 1.68 \\
\hline
\end{tabular}

Table BI. Test data - Baseline Rocket

\begin{tabular}{|c|c|c|c|c|c|c|c|c|c|c|c|c|}
\hline Ptot(kPa) & MR & $\%$ N2 & Isp(sec) & $c^{*}(\mathrm{~m} / \mathrm{sec})$ & $\mathrm{Cf}$ & Fvac(N) & mtot $(g / s)$ & Isp-eff & $c^{*}$ eff & Cf-eff & Phead(kPa) & Pamb(kPa) \\
\hline 462.3 & 3.99 & 0.0 & 331 & 2274 & 1.427 & 84.5 & 26.0 & 0.715 & 0.915 & 0.781 & 1.70 & 1.79 \\
\hline 462.3 & 3.97 & 0.0 & 328 & 2269 & 1.419 & 84.3 & 26.2 & 0.708 & 0.912 & 0.777 & 1.70 & 1.71 \\
\hline 462.3 & 3.97 & 2.4 & 335 & 2210 & 1.488 & 88.4 & 26.9 & 0.731 & 0.898 & 0.816 & 2.88 & 1.61 \\
\hline 462.3 & 4.01 & 2.5 & 335 & 2207 & 1.486 & 88.1 & 26.8 & 0.732 & 0.898 & 0.814 & 2.75 & 1.66 \\
\hline 469.2 & 3.99 & 2.4 & 334 & 2198 & 1.490 & 89.6 & 27.4 & 0.729 & 0.893 & 0.816 & 3.15 & 1.70 \\
\hline 469.2 & 4.02 & 4.3 & 333 & 2152 & 1.517 & 91.5 & 28.0 & 0.734 & 0.883 & 0.831 & 3.55 & 1.68 \\
\hline 476.1 & 3.99 & 0.0 & 329 & 2284 & 1.412 & 86.2 & 26.7 & 0.710 & 0.919 & 0.773 & 1.70 & 1.79 \\
\hline 476.1 & 4.07 & 0.8 & 331 & 2228 & 1.456 & 88.8 & 27.4 & 0.718 & 0.902 & 0.796 & 2.36 & 1.75 \\
\hline 476.1 & 4.11 & 1.9 & 331 & 2186 & 1.483 & 90.4 & 27.9 & 0.722 & 0.890 & 0.809 & 2.88 & 1.75 \\
\hline 476.1 & 4.03 & 9.7 & 320 & 2062 & 1.520 & 92.8 & 29.6 & 0.724 & 0.866 & 0.835 & 3.95 & 1.57 \\
\hline 558.9 & 4.04 & 0.0 & 329 & 2262 & 1.427 & 101.8 & 31.5 & 0.711 & 0.910 & 0.781 & 1.96 & 1.73 \\
\hline 558.9 & 4.10 & 0.0 & 332 & 2260 & 1.442 & 103.4 & 31.7 & 0.717 & 0.912 & 0.788 & 2.49 & 1.77 \\
\hline 558.9 & 4.12 & 0.9 & 333 & 2243 & 1.458 & 105.0 & 32.1 & 0.723 & 0.909 & 0.796 & 3.15 & 1.70 \\
\hline 558.9 & 4.15 & 1.9 & 332 & 2201 & 1.480 & 106.6 & 32.7 & 0.724 & 0.897 & 0.808 & 3.68 & 1.70 \\
\hline 565.8 & 4.06 & 2.5 & 337 & 2224 & 1.484 & 107.2 & 32.4 & 0.736 & 0.905 & 0.812 & 3.95 & 1.70 \\
\hline 565.8 & 4.13 & 4.5 & 330 & 2152 & 1.503 & 108.6 & 33.6 & 0.728 & 0.886 & 0.822 & 4.34 & 1.62 \\
\hline 565.8 & 4.11 & 9.9 & 318 & 2056 & 1.518 & 109.8 & 35.2 & 0.720 & 0.866 & 0.832 & 4.87 & 1.61 \\
\hline 669.3 & 4.00 & 0.0 & 335 & 2286 & 1.438 & 123.9 & 37.6 & 0.723 & 0.918 & 0.788 & 3.42 & 1.72 \\
\hline 669.3 & 3.98 & 0.9 & 335 & 2258 & 1.455 & 124.5 & 37.8 & 0.726 & 0.910 & 0.798 & 3.82 & 1.68 \\
\hline 669.3 & 3.99 & 2.0 & 334 & 2222 & 1.473 & 126.2 & 38.5 & 0.728 & 0.900 & 0.808 & 4.47 & 1.63 \\
\hline 669.3 & 4.07 & 2.6 & 332 & 2227 & 1.461 & 125.3 & 38.5 & 0.726 & 0.906 & 0.800 & 4.60 & 1.61 \\
\hline 669.3 & 4.06 & 4.7 & 331 & 2188 & 1.485 & 127.5 & 39.2 & 0.731 & 0.899 & 0.814 & 5.26 & 1.55 \\
\hline 669.3 & 3.98 & 10.1 & 317 & 2085 & 1.490 & 127.4 & 41.0 & 0.718 & 0.875 & 0.820 & 5.80 & 1.62 \\
\hline 676.2 & 4.10 & 0.0 & 330 & 2292 & 1.413 & 122.9 & 37.9 & 0.713 & 0.923 & 0.773 & 2.36 & 1.83 \\
\hline
\end{tabular}

Table B2. Test data, Rocket-in-a-Duct, $6.18 \mathrm{~cm}$ dia., 5 dia. Long 


\begin{tabular}{|c|c|c|c|c|c|c|c|c|c|c|c|c|}
\hline Ptot(kPa) & MR & $\%$ N2 & Isp(sec) & $c^{*}(\mathrm{~m} / \mathrm{sec})$ & Cf & Fvac(N) & $\operatorname{mtot}(g / s)$ & Isp-eff & $c^{*}$-eff & Cf-eff & Phead(kPa) & Pamb(kPa) \\
\hline 462.3 & 3.91 & 0.0 & 328 & 2269 & 1.419 & 84.8 & 26.3 & 0.724 & 0.910 & 0.796 & 2.75 & 1.58 \\
\hline 462.3 & 4.09 & 0.0 & 318 & 2190 & 1.425 & 84.2 & 26.9 & 0.703 & 0.884 & 0.796 & 2.62 & 1.44 \\
\hline 462.3 & 3.91 & 4.3 & 327 & 2177 & 1.473 & 88.0 & 27.4 & 0.736 & 0.890 & 0.827 & 5.93 & 1.45 \\
\hline 462.3 & 3.91 & 10.0 & 312 & 2065 & 1.481 & 88.4 & 28.9 & 0.722 & 0.866 & 0.833 & 6.06 & 1.61 \\
\hline 469.2 & 4.09 & 0.0 & 323 & 2241 & 1.413 & 84.8 & 26.8 & 0.714 & 0.905 & 0.789 & 2.75 & 1.56 \\
\hline 469.2 & 3.90 & 2.4 & 329 & 2210 & 1.462 & 87.4 & 27.0 & 0.734 & 0.896 & 0.821 & 5.40 & 1.49 \\
\hline 476.1 & 4.05 & 0.0 & 325 & 2233 & 1.425 & 87.6 & 27.5 & 0.718 & 0.900 & 0.797 & 2.75 & 1.49 \\
\hline 476.1 & 4.14 & 0.4 & 328 & 2230 & 1.442 & 88.0 & 27.4 & 0.727 & 0.903 & 0.804 & 3.68 & 1.52 \\
\hline 476.1 & 4.20 & 0.9 & 324 & 2216 & 1.434 & 87.7 & 27.6 & 0.720 & 0.902 & 0.799 & 4.21 & 1.56 \\
\hline 476.1 & 4.17 & 1.9 & 327 & 2195 & 1.460 & 89.1 & 27.8 & 0.730 & 0.896 & 0.814 & 5.00 & 1.52 \\
\hline 558.9 & 4.15 & 0.4 & 326 & 2236 & 1.430 & 102.8 & 32.2 & 0.722 & 0.905 & 0.798 & 4.47 & 1.63 \\
\hline 565.8 & 4.20 & 0.0 & 322 & 2239 & 1.411 & 102.3 & 32.3 & 0.756 & 0.906 & 0.787 & 3.42 & 1.68 \\
\hline 565.8 & 4.20 & 0.9 & 324 & 2202 & 1.443 & 104.5 & 32.8 & 0.720 & 0.895 & 0.804 & 5.13 & 1.60 \\
\hline 572.7 & 4.15 & 0.0 & 324 & 2258 & 1.409 & 103.2 & 32.4 & 0.716 & 0.912 & 0.786 & 3.42 & 1.66 \\
\hline 572.7 & 4.20 & 1.9 & 323 & 2189 & 1.447 & 106.0 & 33.4 & 0.721 & 0.893 & 0.807 & 6.19 & 1.56 \\
\hline 572.7 & 4.16 & 9.8 & 308 & 2066 & 1.464 & 107.4 & 35.5 & 0.713 & 0.871 & 0.820 & 7.51 & 1.97 \\
\hline 579.6 & 4.09 & 2.3 & 330 & 2235 & 1.447 & 107.2 & 33.1 & 0.737 & 0.910 & 0.809 & 6.59 & 1.45 \\
\hline 579.6 & 4.16 & 4.3 & 322 & 2164 & 1.459 & 108.9 & 34.5 & 0.726 & 0.891 & 0.816 & 7.38 & 1.60 \\
\hline 662.4 & 4.09 & 0.0 & 323 & 2269 & 1.395 & 119.1 & 37.6 & 0.713 & 0.914 & 0.780 & 4.08 & 1.84 \\
\hline 662.4 & 4.07 & 0.4 & 328 & 2259 & 1.423 & 121.1 & 37.6 & 0.726 & 0.911 & 0.796 & 5.40 & 1.92 \\
\hline 662.4 & 4.10 & 0.9 & 328 & 2250 & 1.429 & 121.9 & 37.9 & 0.728 & 0.910 & 0.799 & 6.19 & 1.66 \\
\hline 662.4 & 4.12 & 1.9 & 327 & 2218 & 1.446 & 123.2 & 38.4 & 0.729 & $0 . \overline{901}$ & 0.809 & 7.25 & 1.66 \\
\hline 669.3 & 4.15 & 2.5 & 326 & 2200 & 1.452 & 124.1 & 38.8 & 0.729 & 0.897 & 0.812 & 7.91 & 1.65 \\
\hline 676.2 & 3.99 & 4.6 & 323 & 2189 & 1.448 & 126.1 & 39.7 & 0.728 & 0.896 & 0.813 & 8.57 & 1.80 \\
\hline 683.1 & 4.01 & 0.0 & 328 & 2283 & 1.408 & 122.8 & 38.2 & 0.724 & 0.917 & 0.789 & 4.21 & 1.82 \\
\hline 683.1 & 3.96 & 9.8 & 311 & 2083 & 1.463 & 127.5 & 41.8 & 0.719 & 0.872 & 0.824 & 8.57 & 2.27 \\
\hline
\end{tabular}

Table B3. Test Data, Rocket-in-a-Duct, $4.98 \mathrm{~cm}$ dia., 5 dia. Long 


\begin{tabular}{|c|c|c|c|c|c|c|c|c|c|c|c|c|}
\hline Ptot(kPa) & MR & $\%$ N2 & Isp(sec) & $c^{*}(\mathrm{~m} / \mathrm{sec})$ & $\mathrm{Cf}$ & $F v a c(N)$ & mtot $(g / s)$ & Isp-eff & $c^{*}-e f f$ & Cf-eff & Phead(kPa) & Pamb(kPa) \\
\hline 462.3 & 4.01 & 0.0 & 320 & 2167 & 1.449 & 86.4 & 27.5 & 0.691 & 0.873 & 0.793 & 1.57 & 1.70 \\
\hline 462.3 & 4.06 & 0.0 & 317 & 2166 & 1.436 & 85.7 & 27.5 & 0.685 & 0.874 & 0.785 & 1.70 & 1.73 \\
\hline 462.3 & 4.02 & 2.5 & 327 & 2130 & 1.508 & 90.1 & 28.0 & 0.715 & 0.867 & 0.825 & 3.15 & 1.61 \\
\hline 462.3 & 4.10 & 9.6 & 311 & 1962 & 1.554 & 92.8 & 30.4 & 0.704 & 0.826 & 0.852 & 3.68 & 1.70 \\
\hline 469.2 & 3.97 & 0.9 & 325 & 2174 & 1.466 & 87.7 & 27.5 & 0.705 & 0.877 & 0.803 & 2.23 & 1.64 \\
\hline 469.2 & 4.00 & 1.9 & 327 & 2154 & 1.489 & 89.0 & 27.7 & 0.712 & 0.874 & 0.815 & 2.75 & 1.60 \\
\hline 469.2 & 4.06 & 4.3 & 323 & 2085 & 1.520 & $\overline{91.1}$ & 28.7 & 0.712 & 0.856 & 0.832 & 3.55 & 1.61 \\
\hline 476.1 & 4.03 & 0.0 & 323 & 2207 & 1.436 & 87.6 & 27.6 & 0.698 & 0.889 & 0.785 & 1.70 & 1.75 \\
\hline 476.1 & 4.25 & 0.0 & 317 & 2142 & 1.452 & 88.3 & 28.4 & 0.686 & 0.870 & 0.789 & 1.70 & 1.73 \\
\hline 476.1 & 4.09 & 0.3 & 322 & 2172 & 1.453 & 88.6 & 28.0 & 0.697 & 0.878 & 0.793 & 2.09 & 1.67 \\
\hline 558.9 & 4.08 & 0.0 & 327 & 2224 & 1.442 & 103.6 & 32.3 & 0.706 & 0.896 & 0.788 & 1.96 & 2.04 \\
\hline 558.9 & 4.09 & 0.0 & 325 & 2198 & 1.448 & 103.5 & 32.5 & 0.702 & 0.886 & 0.791 & 1.96 & 2.02 \\
\hline 558.9 & 4.15 & 2.4 & 329 & 2144 & 1.505 & 108.1 & 33.5 & 0.719 & 0.875 & 0.822 & 3.95 & 1.89 \\
\hline 558.9 & 4.12 & 10.0 & 311 & 1996 & 1.529 & 109.3 & 35.8 & 0.705 & 0.841 & 0.838 & 4.47 & 2.03 \\
\hline 565.8 & 4.12 & 0.4 & 327 & 2206 & 1.452 & 105.4 & 32.9 & 0.708 & 0.892 & 0.793 & 2.49 & 2.00 \\
\hline 565.8 & 4.23 & 0.9 & 325 & 2180 & 1.461 & 106.0 & 33.2 & 0.706 & 0.887 & 0.795 & 2.75 & 1.95 \\
\hline 565.8 & 4.24 & 1.9 & 327 & 2157 & 1.487 & 108.0 & 33.7 & 0.714 & 0.881 & 0.810 & 3.42 & 1.93 \\
\hline 565.8 & 4.36 & 4.4 & 322 & 2093 & 1.511 & 110.1 & 34.8 & 0.712 & 0.868 & 0.821 & 4.21 & 1.90 \\
\hline 565.8 & 4.30 & 4.4 & 325 & 2095 & 1.519 & 110.3 & 34.6 & 0.718 & 0.867 & 0.827 & 4.34 & 1.90 \\
\hline 669.3 & 4.11 & 0.0 & 327 & 2245 & 1.427 & 122.6 & 38.2 & 0.706 & 0.905 & 0.780 & 2.36 & 2.35 \\
\hline 669.3 & 4.05 & 0.0 & 327 & 2237 & 1.433 & 122.7 & 38.2 & 0.706 & 0.900 & 0.784 & 2.36 & 2.33 \\
\hline 669.3 & 4.17 & 0.4 & 327 & 2211 & 1.452 & 124.8 & 38.8 & 0.708 & 0.895 & 0.792 & 3.02 & 2.33 \\
\hline 669.3 & 4.11 & 0.9 & 331 & 2224 & 1.461 & 125.5 & 38.6 & 0.718 & 0.900 & 0.799 & 3.42 & 2.25 \\
\hline 669.3 & 4.10 & 1.9 & 332 & 2193 & 1.486 & 127.6 & 39.1 & 0.723 & 0.891 & 0.813 & 4.21 & 2.24 \\
\hline 669.3 & 4.13 & 2.5 & 329 & 2156 & 1.494 & 128.4 & 39.8 & 0.719 & 0.879 & 0.817 & 4.60 & 2.21 \\
\hline 669.3 & 4.10 & 4.7 & 327 & 2125 & 1.510 & 129.8 & 40.4 & 0.722 & 0.873 & 0.827 & 5.13 & 2.21 \\
\hline 669.3 & 4.18 & 9.8 & 314 & 2024 & 1.521 & 130.5 & 42.4 & 0.711 & 0.853 & 0.833 & 5.40 & 2.45 \\
\hline
\end{tabular}

Table B4. Test Data, Rocket-in-a-Duct, $6.18 \mathrm{~cm}$ dia., 3 dia. Long 


\begin{tabular}{|c|c|c|c|c|c|c|c|c|c|c|c|c|}
\hline Ptot(kPa) & MR & $\% N_{2}$ & isp(sec) & $c^{\prime \prime}(\mathrm{m} / \mathrm{sec})$ & $\overline{\mathbf{C f}}$ & Fvac(N) & mtot $(g / s)$ & Isp-eff & $c^{n}-\mathrm{eff}$ & Cf-eff & Phead(kPa) & Pamb(kPa) \\
\hline 476.1 & 3.93 & 0.0 & 331 & 2306 & 1.408 & 86.5 & 26.6 & 0.714 & 0.925 & 0.772 & 1.70 & 1.91 \\
\hline 476.1 & 4.21 & 0.0 & 317 & 2191 & 1.420 & 86.9 & 27.9 & 0.686 & 0.888 & 0.773 & 1.70 & 1.75 \\
\hline 476.1 & 4.03 & 0.0 & 323 & 2252 & 1.409 & 86.3 & 27.2 & 0.698 & 0.907 & 0.770 & 1.70 & 1.86 \\
\hline 476.1 & 4.23 & 0.0 & 315 & 2178 & 1.417 & 86.5 & 28.0 & 0.682 & 0.884 & 0.771 & 1.70 & 1.73 \\
\hline 476.1 & 3.98 & 2.4 & 333 & 2217 & 1.474 & 90.7 & 27.7 & 0.727 & 0.901 & 0.808 & 3.28 & 1.65 \\
\hline 476.1 & 3.98 & 4.3 & 328 & 2161 & 1.487 & 90.9 & 28.3 & 0.723 & 0.885 & 0.816 & 3.55 & 1.56 \\
\hline 483.0 & 4.09 & 0.3 & 325 & 2234 & 1.427 & 88.0 & 27.6 & 0.703 & 0.903 & 0.779 & 2.09 & 1.70 \\
\hline 483.0 & 4.10 & 0.8 & 326 & 2216 & 1.441 & 89.4 & 28.0 & 0.707 & 0.898 & 0.787 & 2.36 & 1.75 \\
\hline 483.0 & 4.10 & 1.9 & 326 & 2188 & 1.462 & 90.4 & 28.3 & 0.711 & 0.891 & 0.798 & 2.88 & 1.64 \\
\hline 483.0 & 4.00 & 9.8 & 311 & 2062 & 1.480 & 91.1 & 29.8 & 0.704 & 0.866 & 0.813 & 3.82 & 1.58 \\
\hline 565.8 & 4.24 & 0.0 & 322 & 2247 & 1.405 & 102.0 & 32.3 & 0.697 & 0.911 & 0.765 & 2.09 & 1.83 \\
\hline 572.7 & 4.24 & 0.4 & 326 & 2240 & 1.427 & 104.5 & 32.7 & 0.707 & 0.909 & 0.777 & 2.49 & 1.70 \\
\hline 572.7 & 4.25 & 0.9 & 324 & 2221 & 1.432 & 105.5 & 33.2 & 0.704 & 0.904 & 0.779 & 3.02 & 1.66 \\
\hline 572.7 & 4.34 & 1.9 & 322 & 2180 & 1.450 & 106.9 & 33.8 & 0.703 & 0.894 & 0.788 & 3.55 & 1.61 \\
\hline 579.6 & 4.17 & 0.0 & 324 & 2266 & 1.401 & 103.6 & 32.6 & 0.700 & 0.916 & 0.764 & 2.09 & 1.75 \\
\hline 579.6 & 4.06 & 2.5 & 329 & 2221 & 1.454 & 108.0 & 33.4 & 0.719 & 0.904 & 0.796 & 3.95 & 1.50 \\
\hline 579.6 & 4.29 & 4.4 & 321 & 2139 & 1.472 & 108.9 & 34.6 & 0.709 & 0.885 & 0.802 & 4.34 & 1.58 \\
\hline 579.6 & 4.31 & 9.7 & 305 & 2032 & 1.471 & 108.9 & 36.4 & 0.691 & 0.861 & 0.803 & 4.60 & 1.66 \\
\hline 669.3 & 3.98 & 0.0 & 325 & 2283 & 1.396 & 119.5 & 37.5 & 0.701 & 0.916 & 0.766 & 2.49 & 1.54 \\
\hline 669.3 & 4.11 & 0.8 & 323 & 2231 & 1.420 & 122.3 & 38.6 & 0.700 & 0.902 & 0.776 & 3.42 & 1.52 \\
\hline 669.3 & 4,13 & 1.9 & 324 & 2201 & 1.443 & 124.3 & 39.1 & 0.706 & 0.895 & 0.789 & 4.21 & 1.55 \\
\hline 676.2 & 4.05 & 0.0 & 324 & 2272 & 1.397 & 121.6 & 38.3 & 0.699 & 0.914 & 0.765 & 2.49 & 1.45 \\
\hline 676.2 & 4.05 & 0.4 & 324 & 2260 & 1.404 & 121.4 & 38.2 & 0.701 & 0.911 & 0.768 & 3.02 & 1.50 \\
\hline 676.2 & 4.14 & 0.9 & 321 & 2224 & 1.417 & 122.4 & 38.8 & 0.696 & 0.901 & 0.774 & 3.42 & 1.48 \\
\hline 676.2 & 4.05 & 2.6 & 328 & 2224 & 1.447 & 124.9 & 38.8 & 0.717 & 0.904 & 0.793 & 4.60 & 1.45 \\
\hline 676.2 & 4.12 & 4.6 & 321 & 2167 & 1.454 & 126.5 & 40.1 & 0.708 & 0.891 & 0.796 & 5.00 & 1.59 \\
\hline 676.2 & 4.12 & 9.8 & 307 & 2062 & 1.461 & 126.7 & 42.0 & 0.695 & 0.868 & 0.801 & 5.53 & 1.69 \\
\hline
\end{tabular}

Table B5. Test data, Rocket-in-a-duct, $6.18 \mathrm{~cm}$ dia., 7 dia. long 


\begin{tabular}{|c|c|c|c|c|c|c|c|c|c|c|c|c|}
\hline Ptot(kPa) & MR & $\% \mathrm{~N} 2$ & Isp(sec) & $c^{\star}(\mathrm{m} / \mathrm{sec})$ & $\mathrm{Cf}$ & Fvac(N) & mtot $(g / s)$ & Isp-eff & $c^{*}$-eff & Cf-eff & Phead(kPa) & Pamb(kPa) \\
\hline 476.1 & 4.16 & 0.0 & 319 & 2177 & 1.436 & 87.1 & 27.9 & 0.679 & 0.881 & 0.770 & 1.17 & 1.64 \\
\hline 476.1 & 4.35 & 0.0 & 315 & 2186 & 1.415 & 86.3 & 27.9 & 0.672 & 0.891 & 0.755 & 1.30 & 1.79 \\
\hline 483.0 & 3.88 & 0.0 & 330 & 2281 & 1.417 & 88.1 & 27.2 & 0.702 & 0.914 & 0.767 & 1.30 & 1.86 \\
\hline 483.0 & 4.22 & 0.0 & 316 & 2176 & 1.425 & 88.1 & 28.4 & 0.673 & 0.882 & 0.763 & 1.17 & 1.64 \\
\hline 483.0 & 4.09 & 0.4 & 328 & 2227 & 1.444 & 89.0 & 27.6 & 0.699 & 0.901 & 0.776 & 1.44 & 1.81 \\
\hline 483.0 & 4.04 & 0.9 & 330 & 2234 & 1.448 & 89.6 & 27.7 & 0.705 & 0.904 & 0.780 & 1.57 & 1.75 \\
\hline 483.0 & 4.04 & 1.9 & 332 & 2221 & 1.465 & 91.0 & 27.9 & 0.712 & 0.902 & 0.789 & 1.83 & 1.70 \\
\hline 489.9 & 4.04 & 2.3 & 327 & 2169 & 1.478 & 92.3 & 28.8 & 0.703 & 0.883 & 0.796 & 2.09 & 1.61 \\
\hline 489.9 & 4.06 & 4.2 & 323 & 2114 & 1.500 & 94.2 & 29.7 & 0.701 & 0.868 & 0.809 & 2.23 & 1.55 \\
\hline 489.9 & 4.08 & 9.5 & 314 & 2024 & 1.522 & 95.8 & 31.1 & 0.699 & 0.851 & 0.822 & 2.62 & 1.54 \\
\hline 489.9 & 4.10 & 14.0 & 304 & 1941 & 1.534 & 96.7 & 32.5 & 0.693 & 0.834 & 0.830 & 2.75 & 1.60 \\
\hline 572.7 & 4.09 & 0.0 & 328 & 2265 & 1.422 & 105.0 & 32.6 & 0.698 & 0.913 & 0.765 & 1.44 & 1.84 \\
\hline 579.6 & 4.26 & 0.0 & 318 & 2212 & 1.412 & 105.2 & 33.7 & 0.677 & 0.897 & 0.756 & 1.44 & 1.75 \\
\hline 579.6 & 4.13 & 0.4 & 329 & 2246 & 1.437 & 106.4 & 32.9 & 0.701 & 0.909 & 0.772 & 1.70 & 1.79 \\
\hline 579.6 & 4.14 & 0.9 & 329 & 2237 & 1.444 & 107.2 & 33.2 & 0.703 & 0.907 & 0.776 & 1.96 & 1.75 \\
\hline 579.6 & 4.20 & 1.9 & 328 & 2190 & 1.468 & 108.9 & 33.8 & 0.704 & 0.894 & 0.788 & 2.23 & 1.70 \\
\hline 586.5 & 4.32 & 2.3 & 324 & 2164 & 1.469 & 110.6 & 34.7 & 0.698 & 0.888 & 0.786 & 2.49 & 1.61 \\
\hline 586.5 & 4.32 & 4.3 & 323 & 2122 & 1.491 & 112.3 & 35.4 & 0.702 & 0.878 & 0.799 & 3.02 & 1.61 \\
\hline 586.5 & 4.31 & 9.4 & 314 & 2028 & 1.516 & 114.4 & 37.2 & 0.700 & 0.858 & 0.814 & 3.28 & 1.66 \\
\hline 669.3 & 4.04 & 0.9 & 331 & 2259 & 1.439 & 123.8 & 38.1 & 0.707 & 0.912 & 0.776 & 2.23 & 1.72 \\
\hline 676.2 & 4.08 & 0.0 & 327 & 2264 & 1.417 & 123.5 & 38.5 & 0.695 & 0.912 & 0.763 & 1.70 & 1.74 \\
\hline 676.2 & 4.11 & 1.9 & 329 & 2230 & 1.447 & 125.3 & 38.8 & 0.706 & 0.906 & 0.779 & 2.62 & 1.62 \\
\hline 676.2 & 4.09 & 2.5 & 329 & 2200 & 1.467 & 127.7 & 39.6 & 0.708 & 0.896 & 0.791 & 3.02 & 1.63 \\
\hline 683.1 & 4.02 & 0.0 & 332 & 2296 & 1.416 & 123.7 & 38.0 & 0.706 & 0.922 & 0.764 & 1.70 & 1.81 \\
\hline 683.1 & 4.11 & 0.4 & 331 & 2266 & 1.433 & 125.5 & 38.6 & 0.705 & 0.915 & 0.771 & 2.09 & 1.81 \\
\hline 683.1 & 4.12 & 4.6 & 325 & 2155 & 1.477 & 129.3 & 40.6 & 0.706 & 0.886 & 0.796 & 3.42 & 1.65 \\
\hline 683.1 & 4.15 & 9.6 & 313 & 2048 & 1.497 & 131.2 & 42.7 & 0.697 & 0.862 & 0.808 & 3.82 & 1.70 \\
\hline
\end{tabular}

Table B6. Test data, Rocket-in-a-duct, $7.38 \mathrm{~cm}$ dia., 5 dia. long 


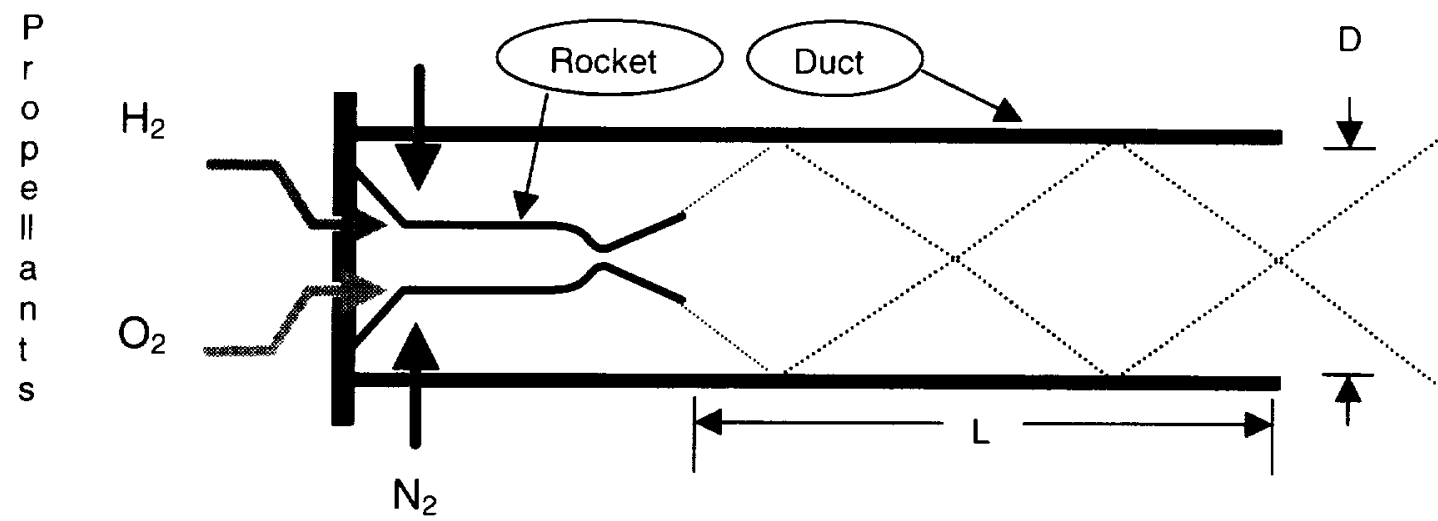

Secondary Flow

Figure 1. Sketch of test apparatus

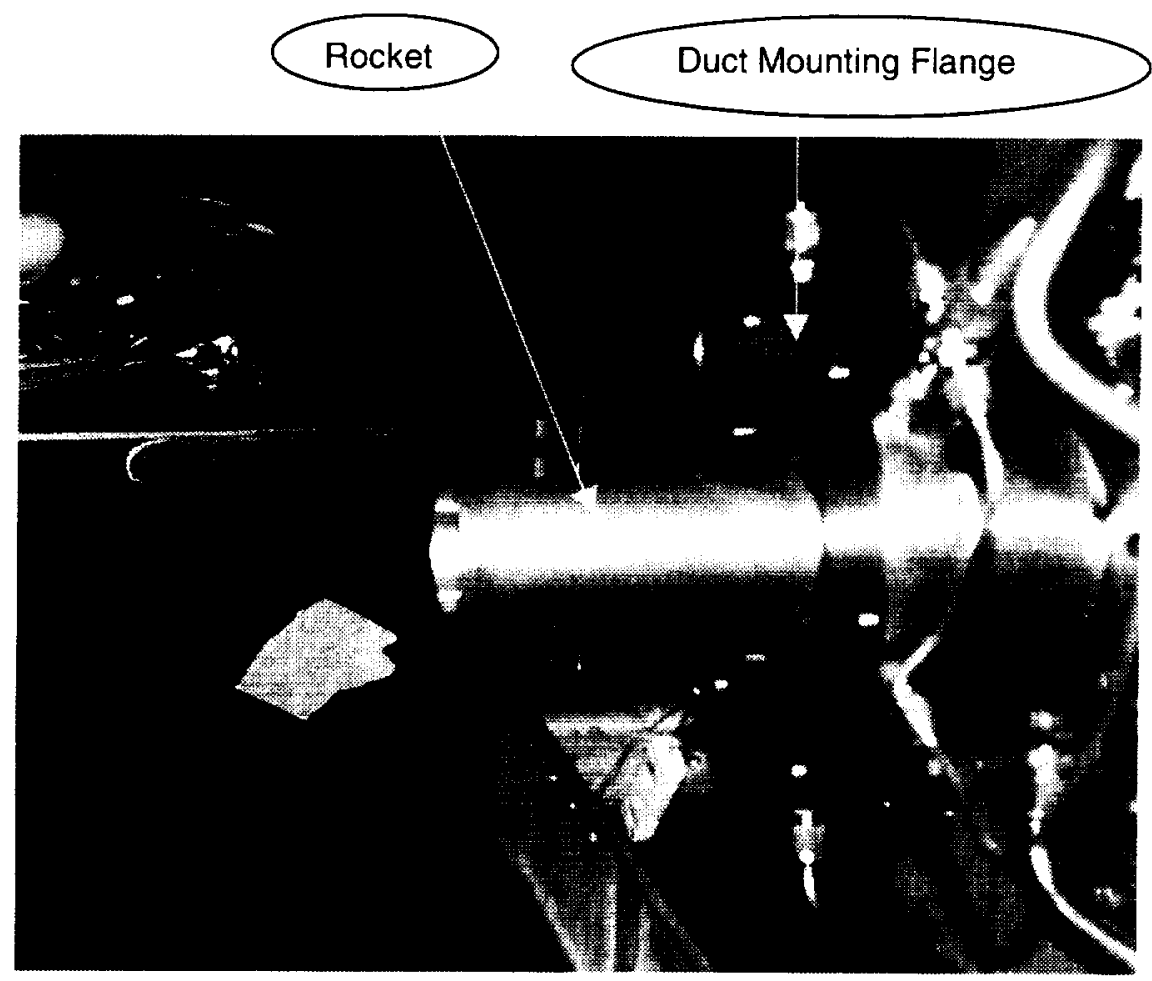

Figure 2. Heat sink type copper rocket in baseline rocket test configuration. 


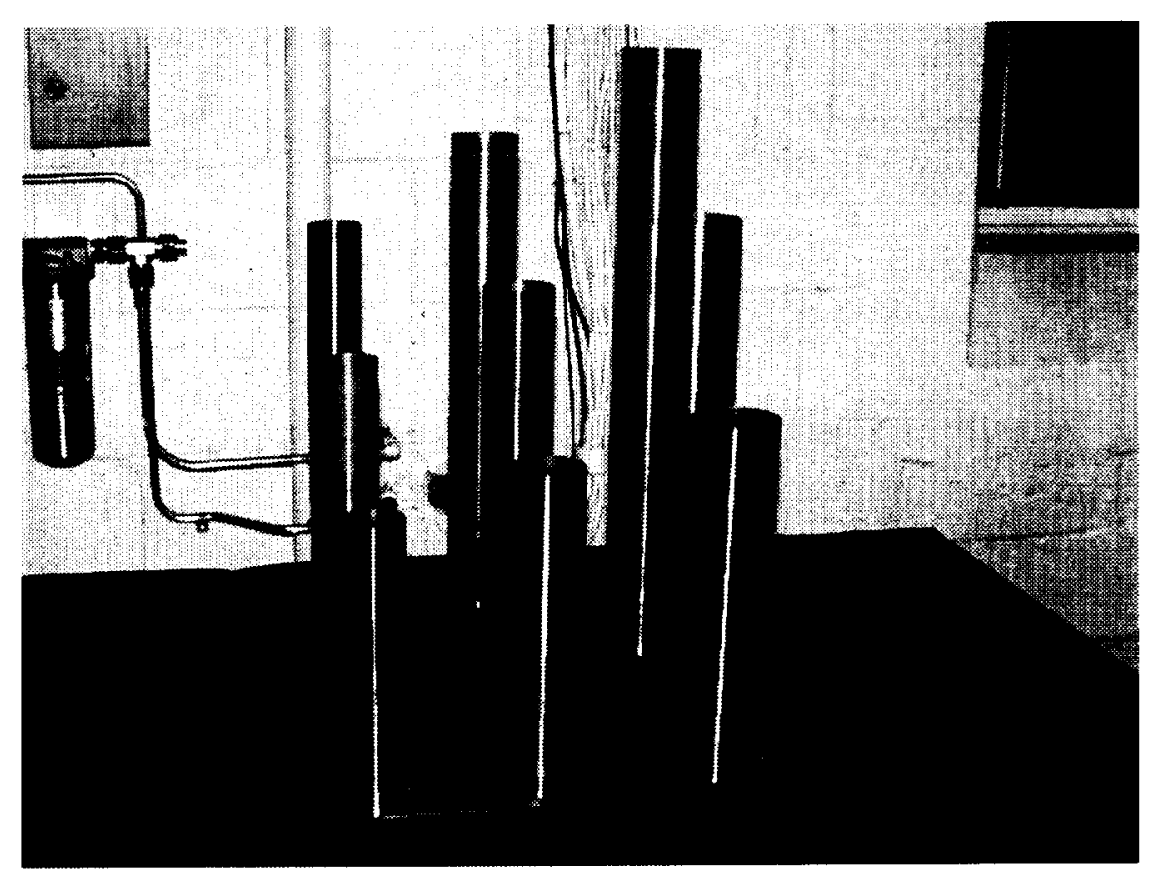

Figure 3. Various copper ducts fabricated for the test series from commercial pipe

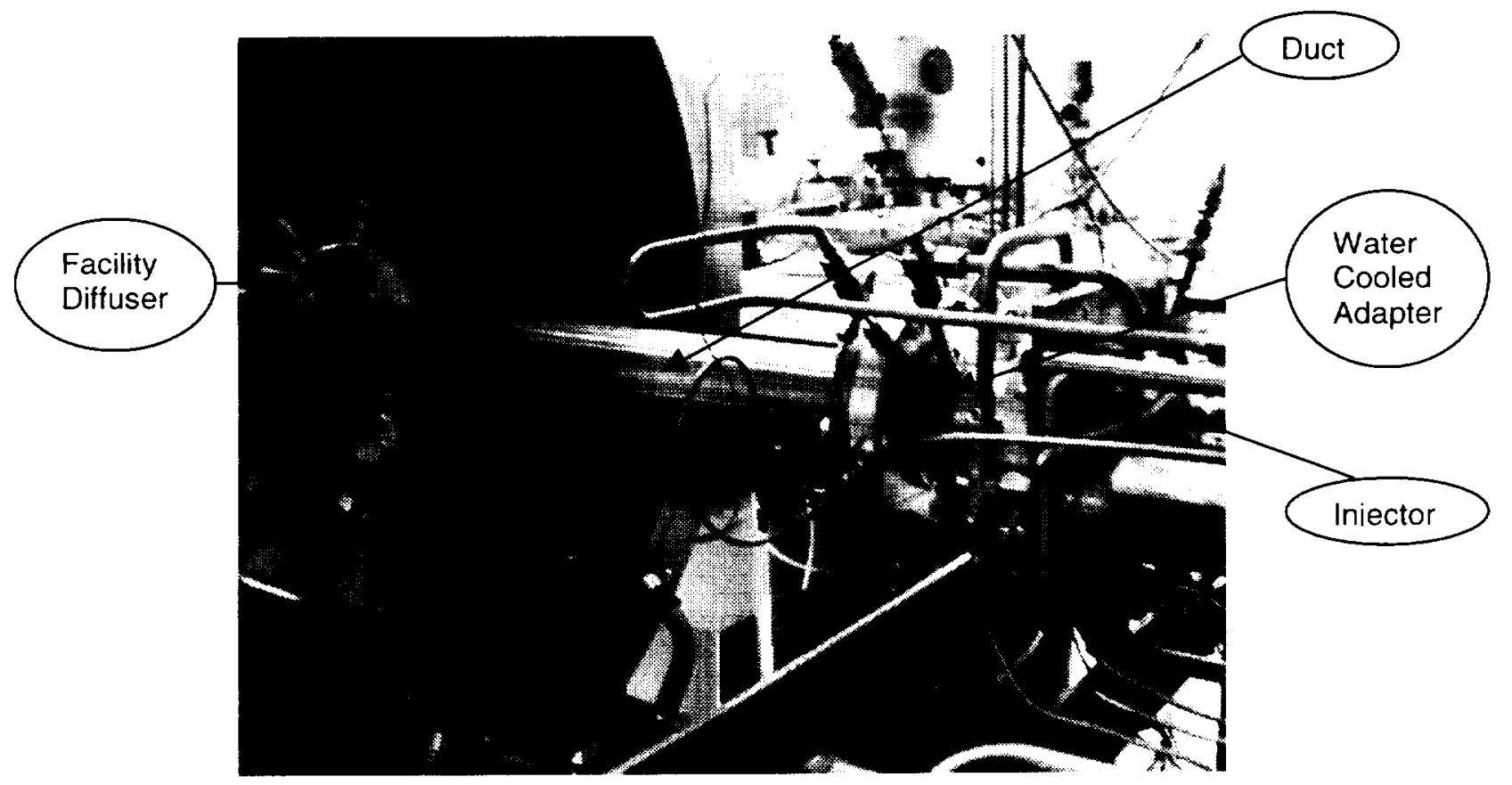

Figure 4. Rocket-in-a-duct test configuration 


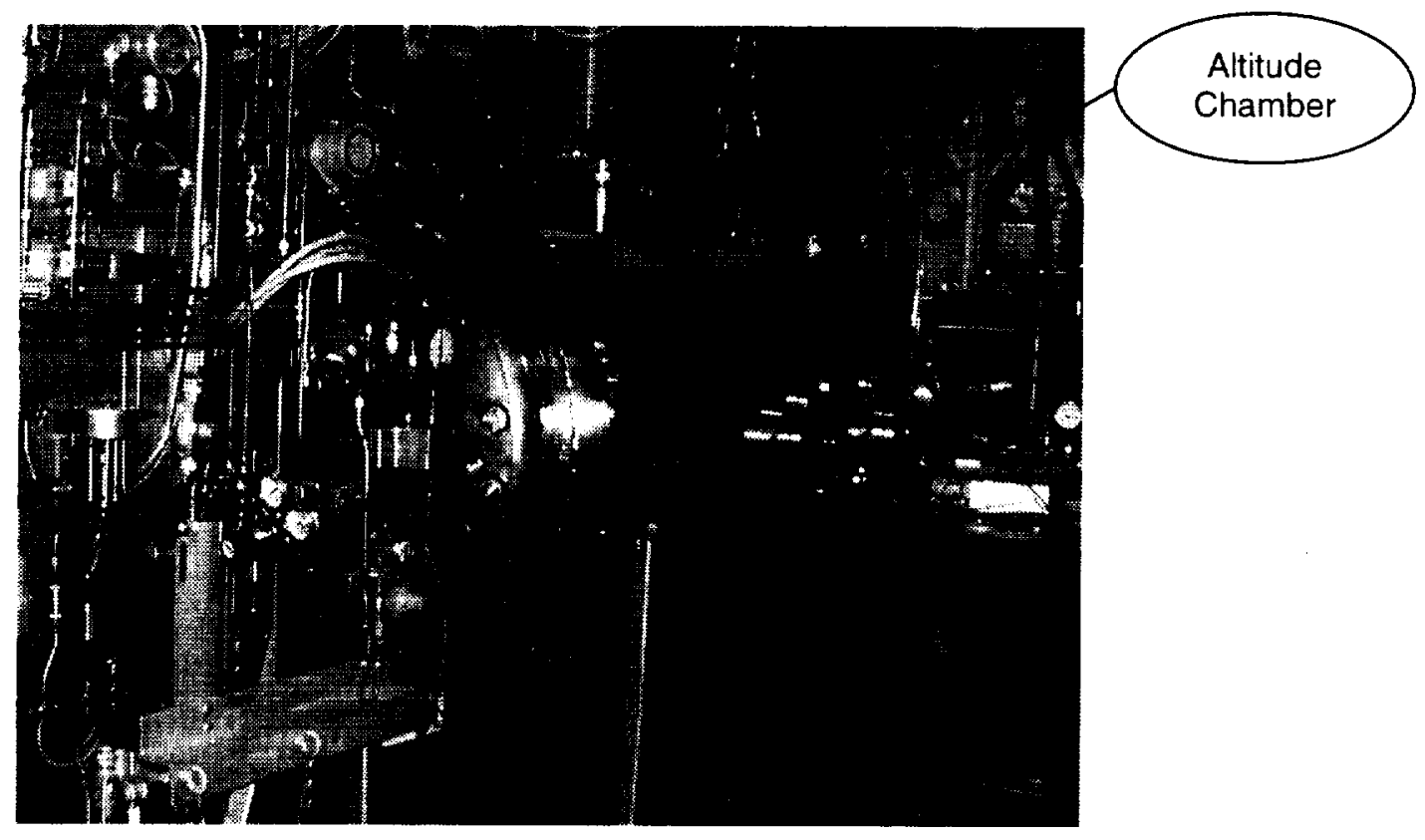

Figure 5. Research Combustion Laboratory Cell-11

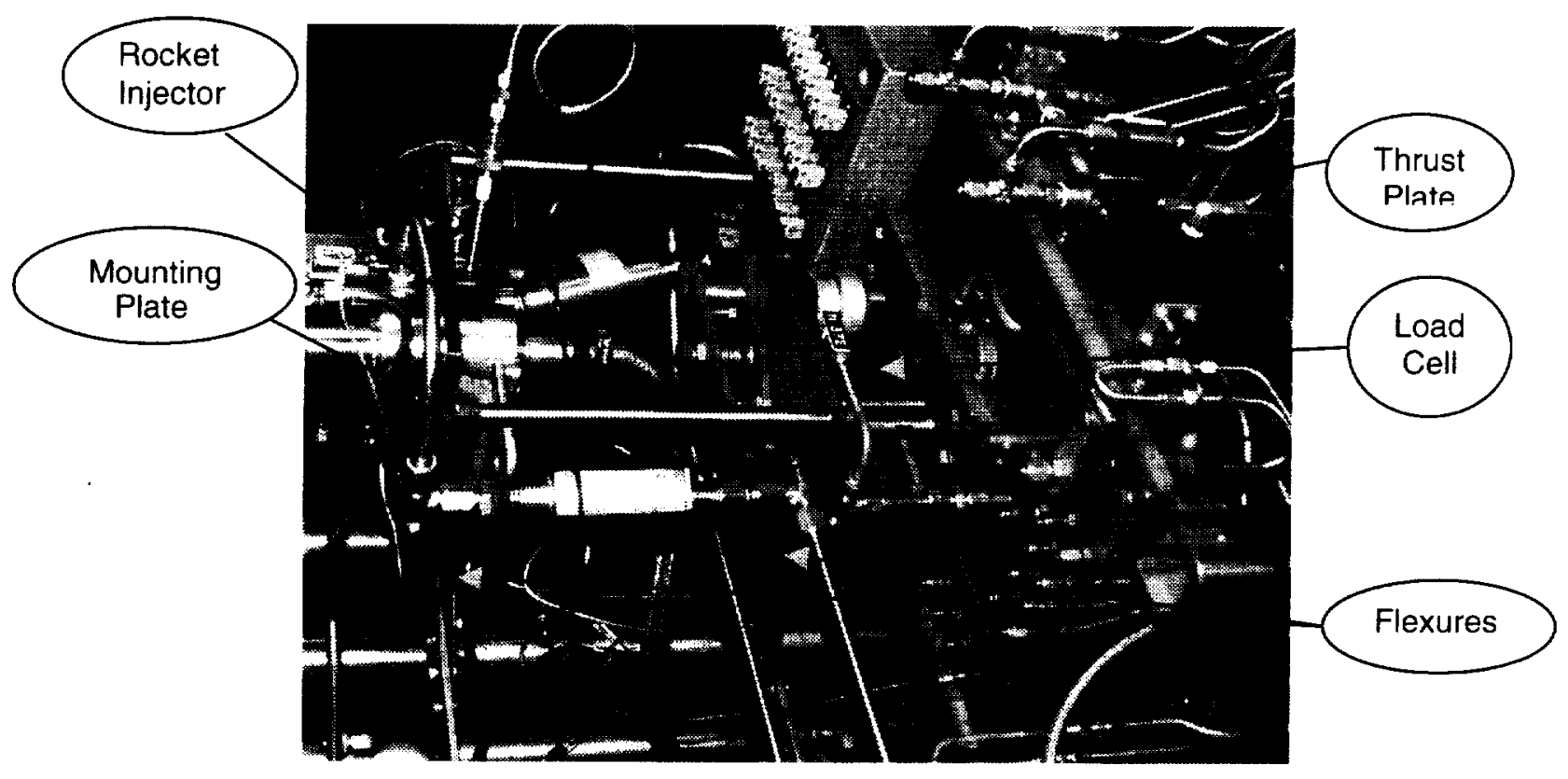

Figure 6. Horizontally-oriented thrust stand 


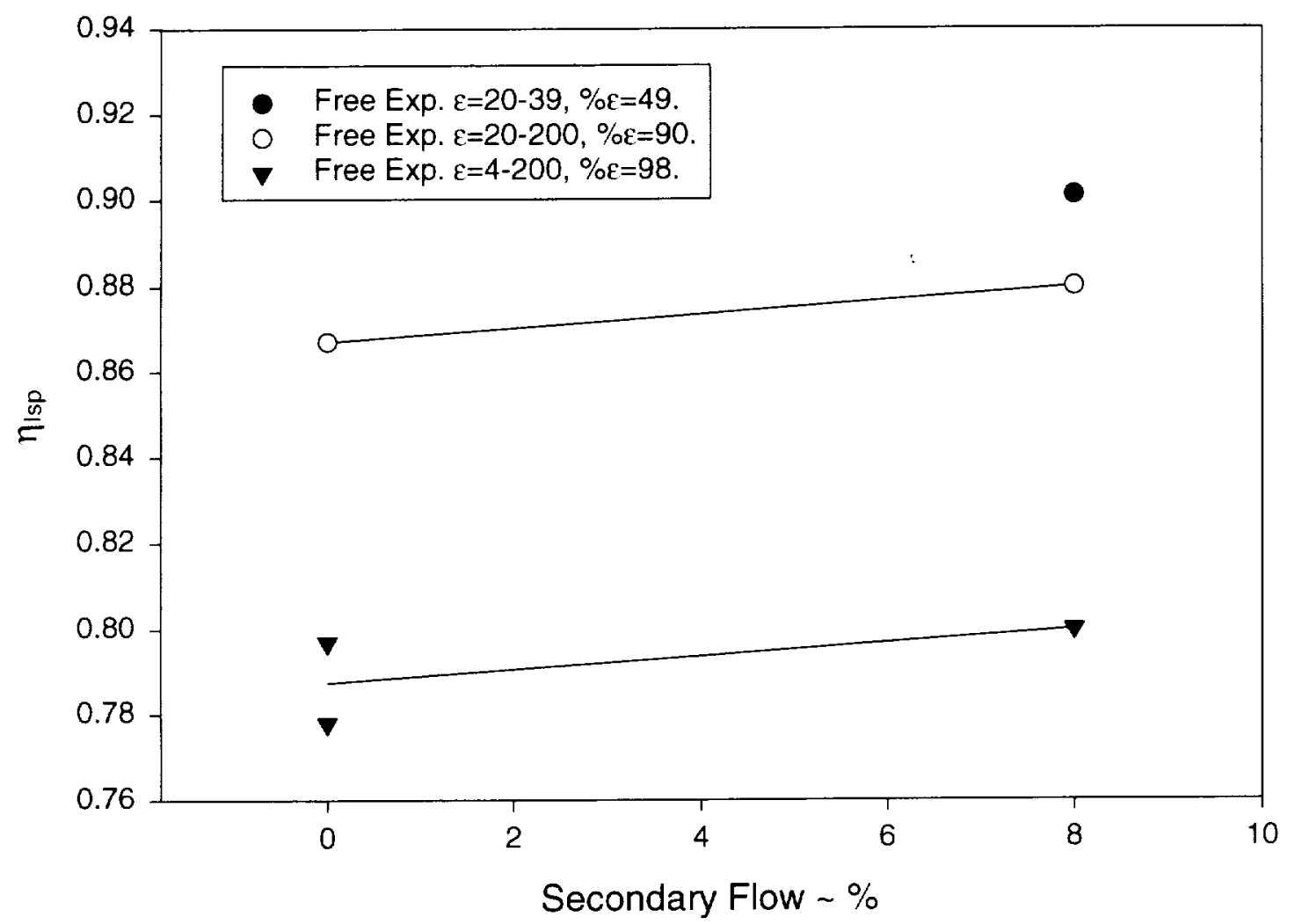

Figure 7. Predicted specific impulse efficiency of a rocket-in-a-duct as a function of secondary flow and free expansion area ratio for $L / D=5$, constant area duct. (CFD. data from Reference 3.) 


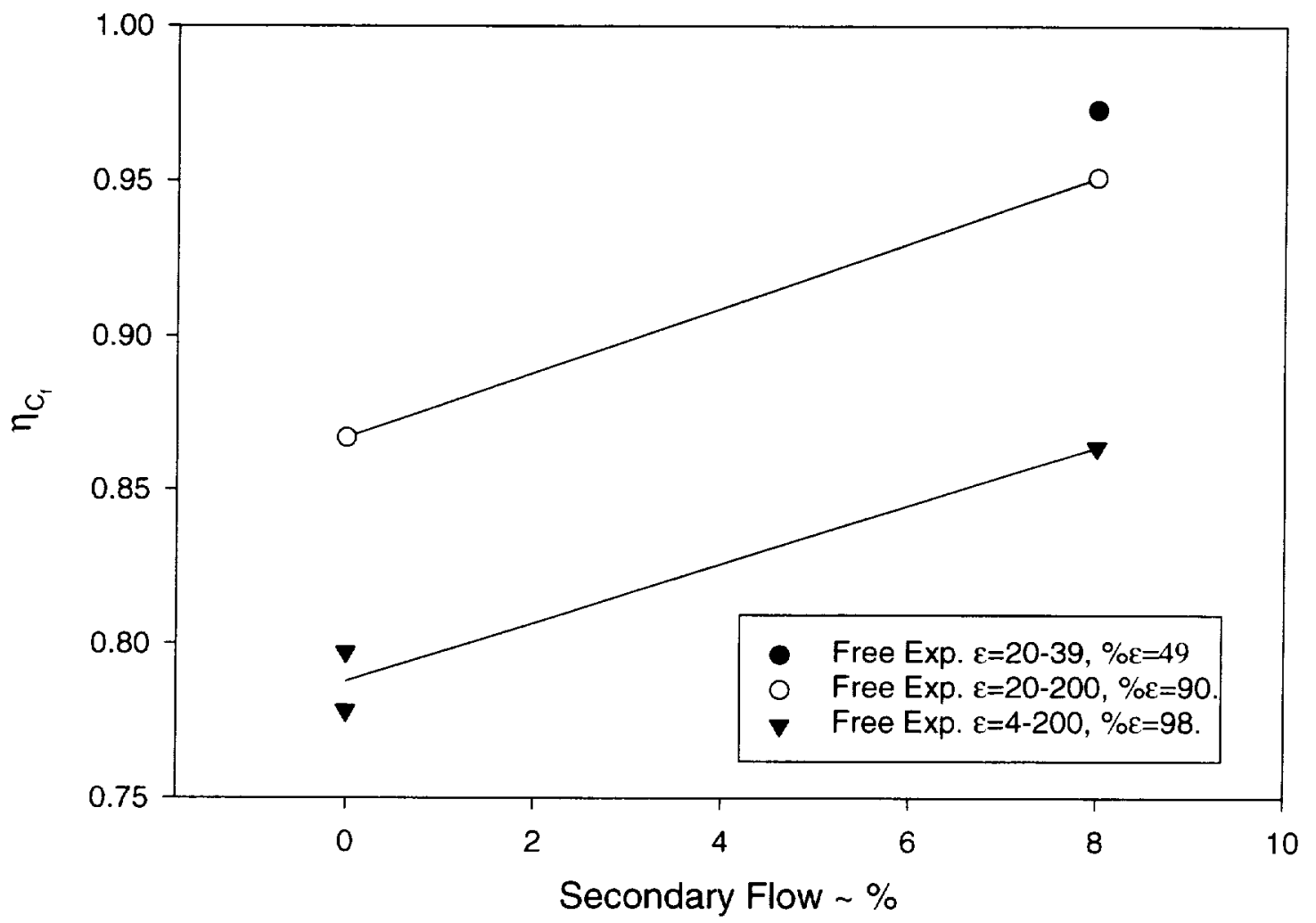

Figure 8. Predicted thrust coefficient efficiency of a rocket-in-a-duct nozzle as a function of secondary flow and free expansion area ratio for $\mathrm{L} / \mathrm{D}=5$, constant area duct. (CFD data from Reference 3.) 


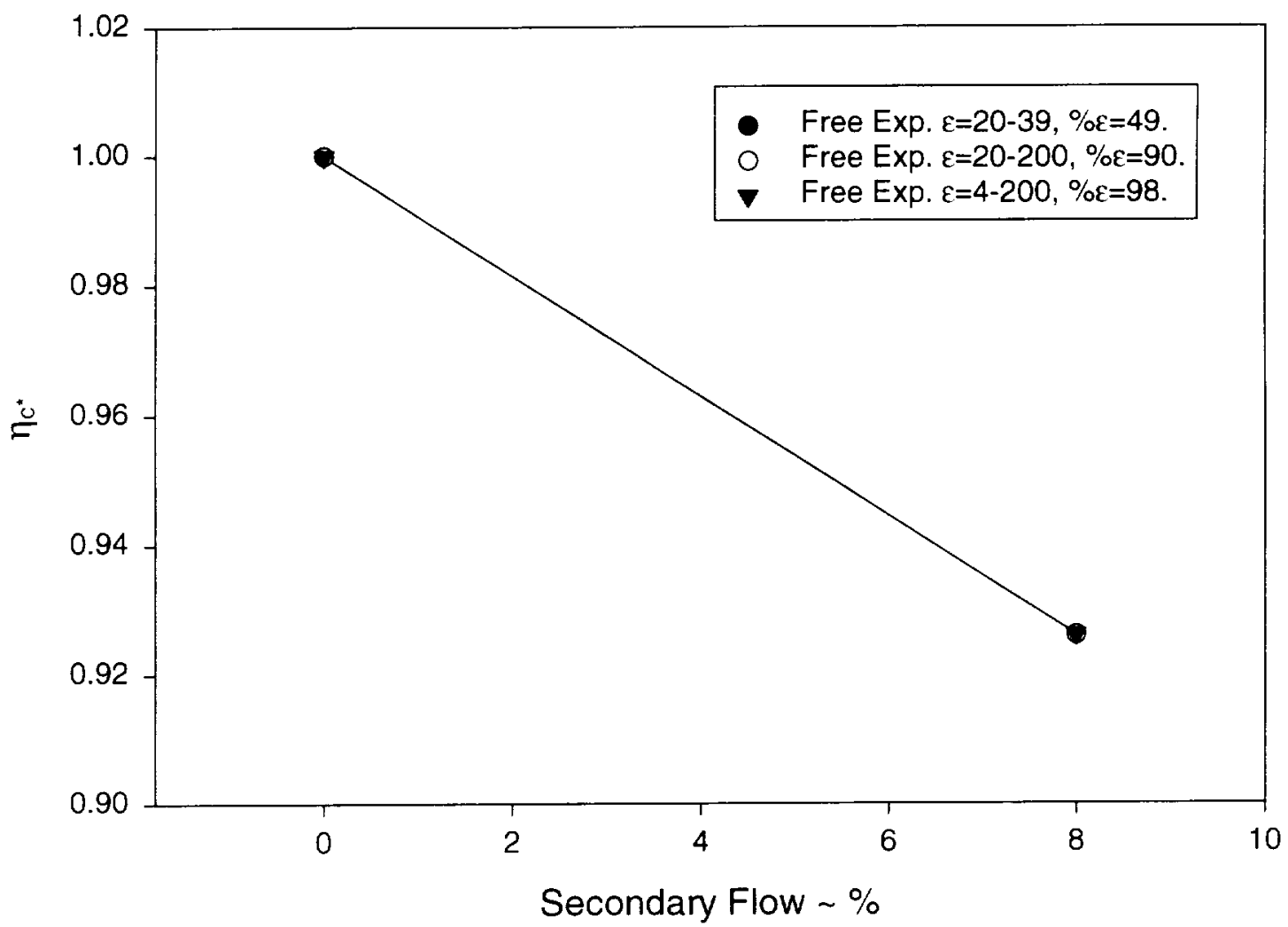

Figure 9. Characteristic velocity efficiency of a rocket-in-a-duct as a function of secondary flow and free expansion area ratio for $L / D=5$, constant area duct. (CFD data from Reference 3.) 


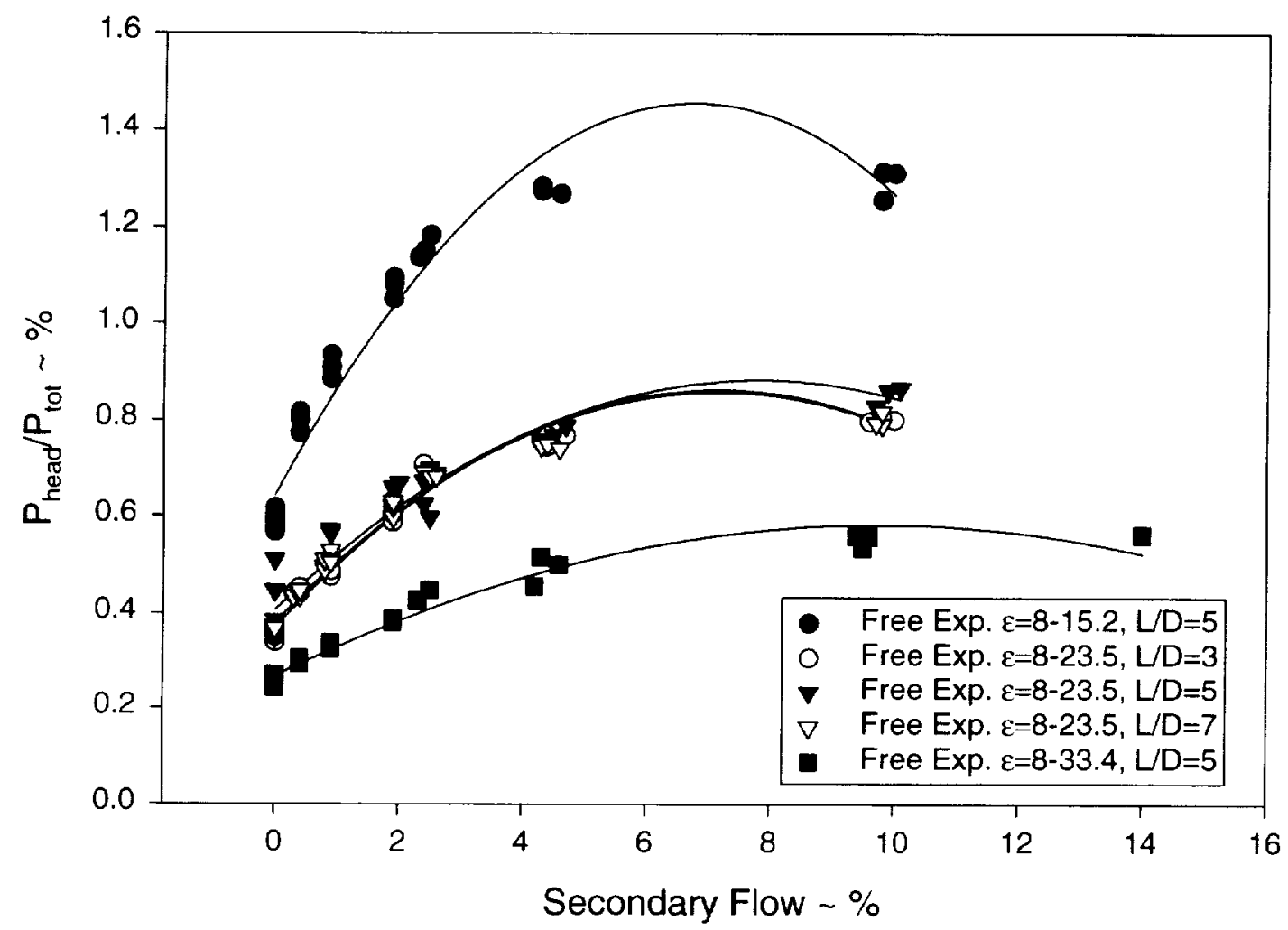

Figure 10. Ratio of duct head end pressure to rocket chamber total pressure. 


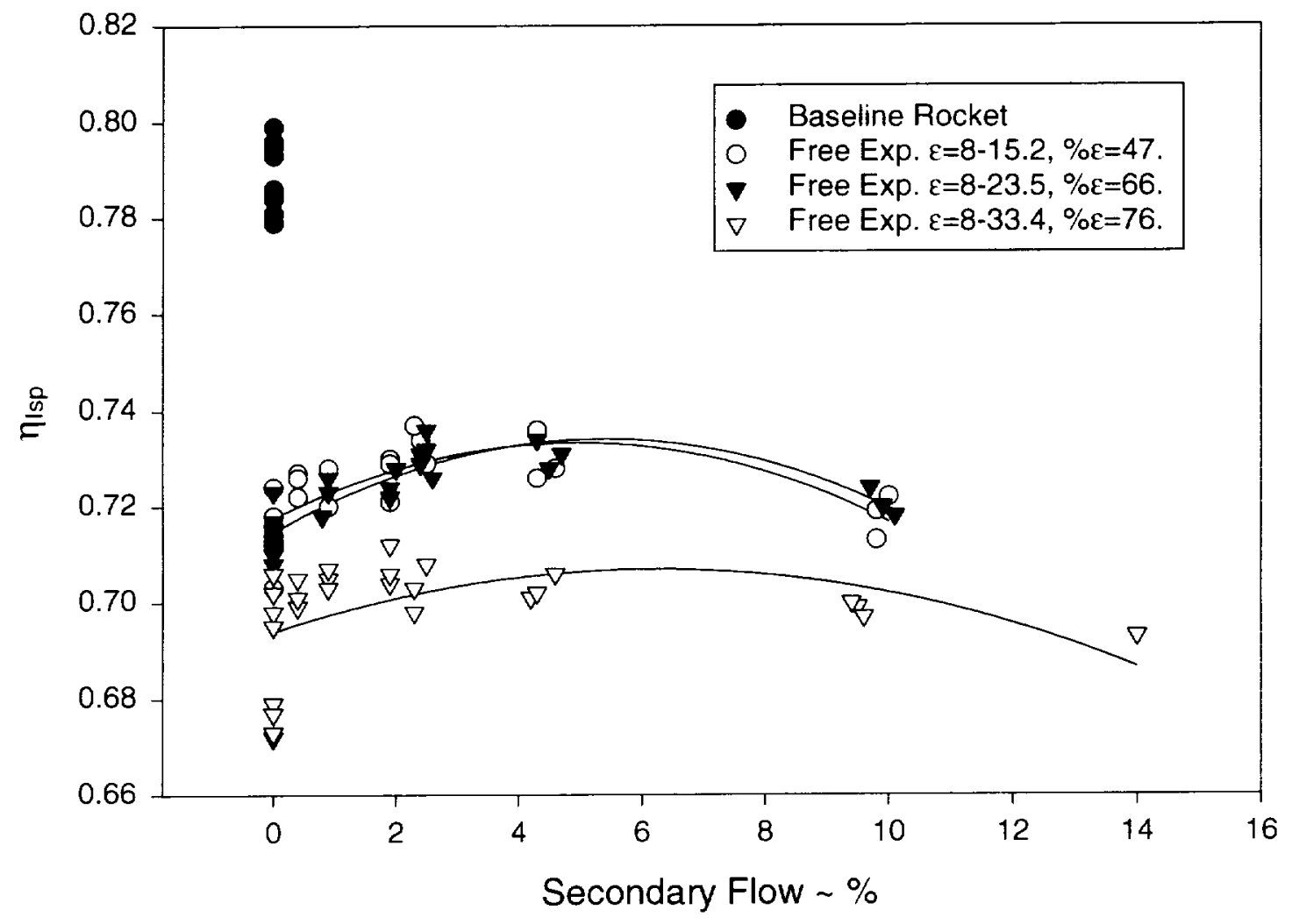

Figure 11. Specific impulse efficiency of rocket-in-a-duct for $L / D=5$ 


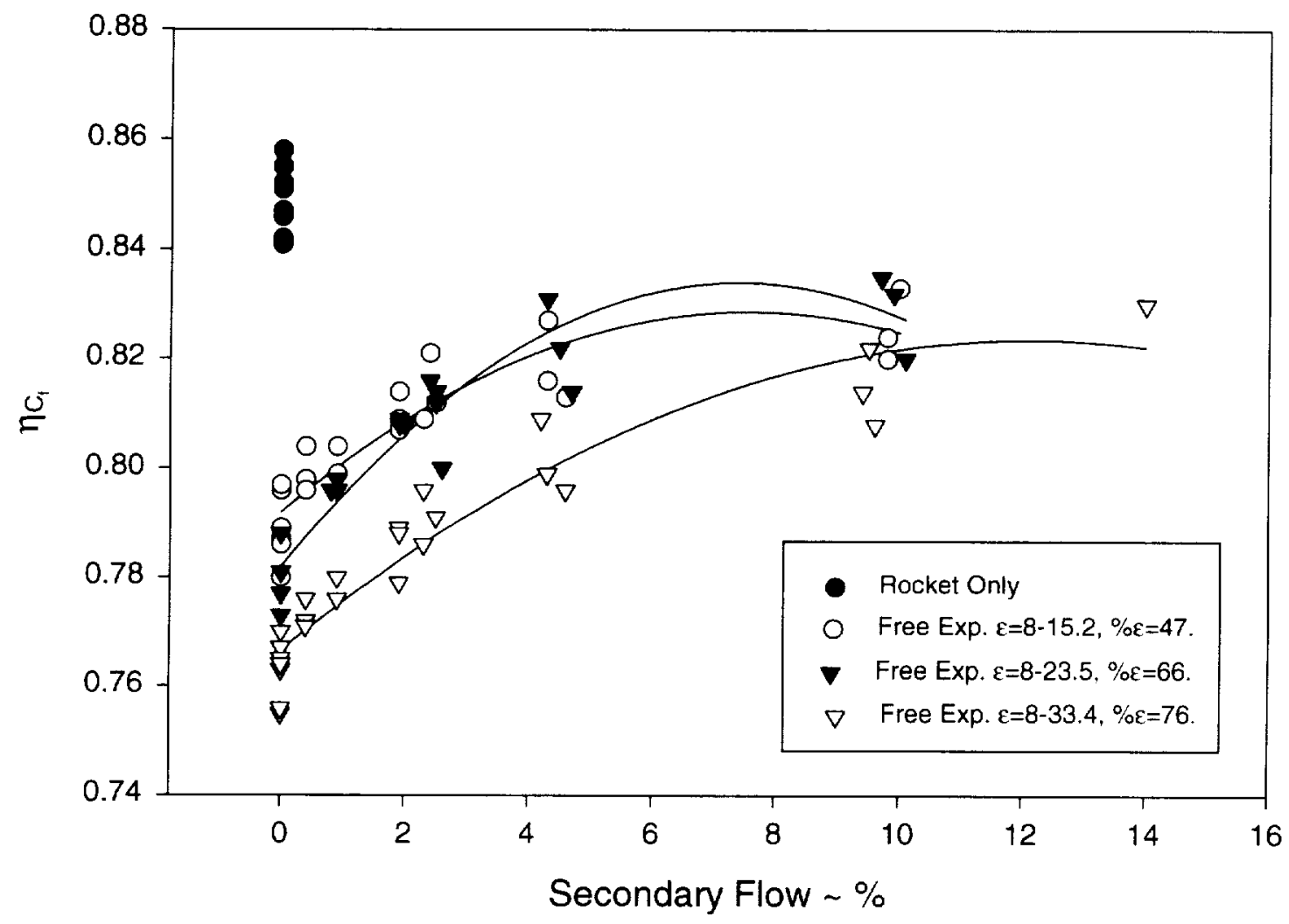

Figure 12. Thrust coefficient efficiency of rocket-in-a-duct for $\mathrm{L} / \mathrm{D}=5$. 


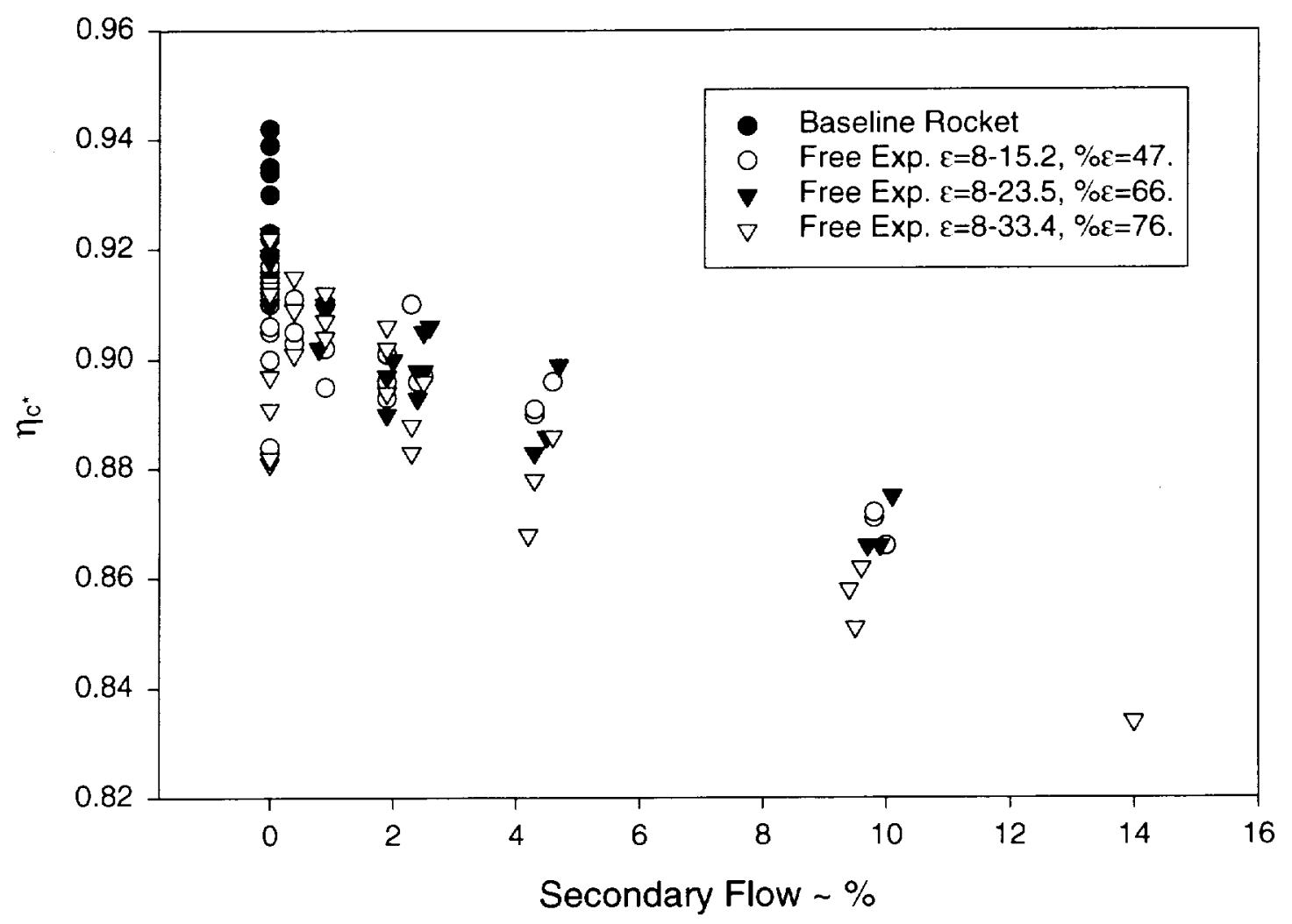

Figure 13. Characteristic velocity efficiency of rocket-in-a-duct for $L / D=5$. 


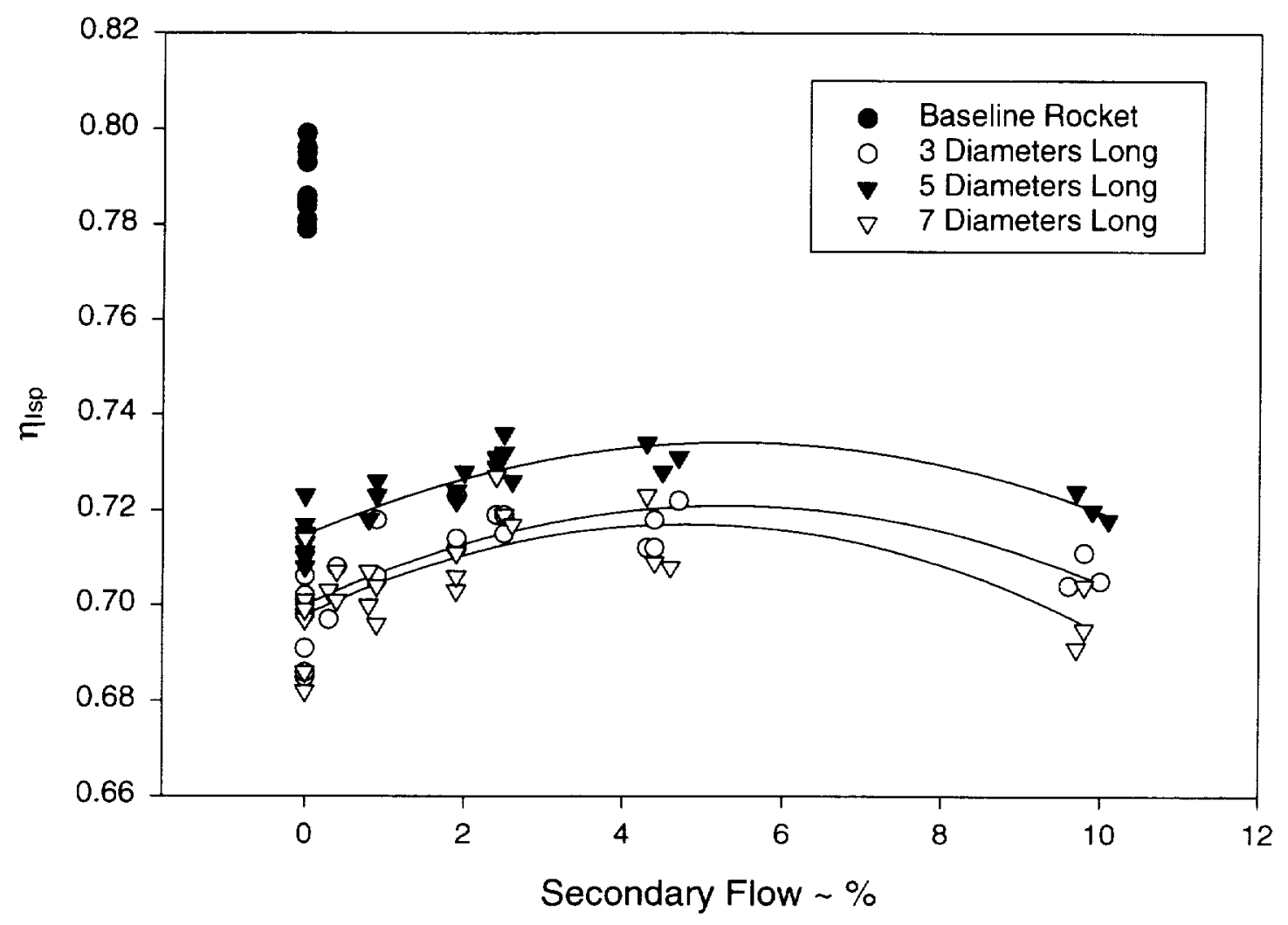

Figure 14. Specific impulse efficiency of rocket-in-a-duct with free expansion $\varepsilon=8-23.5$ as a function of percent secondary flow and length of duct 


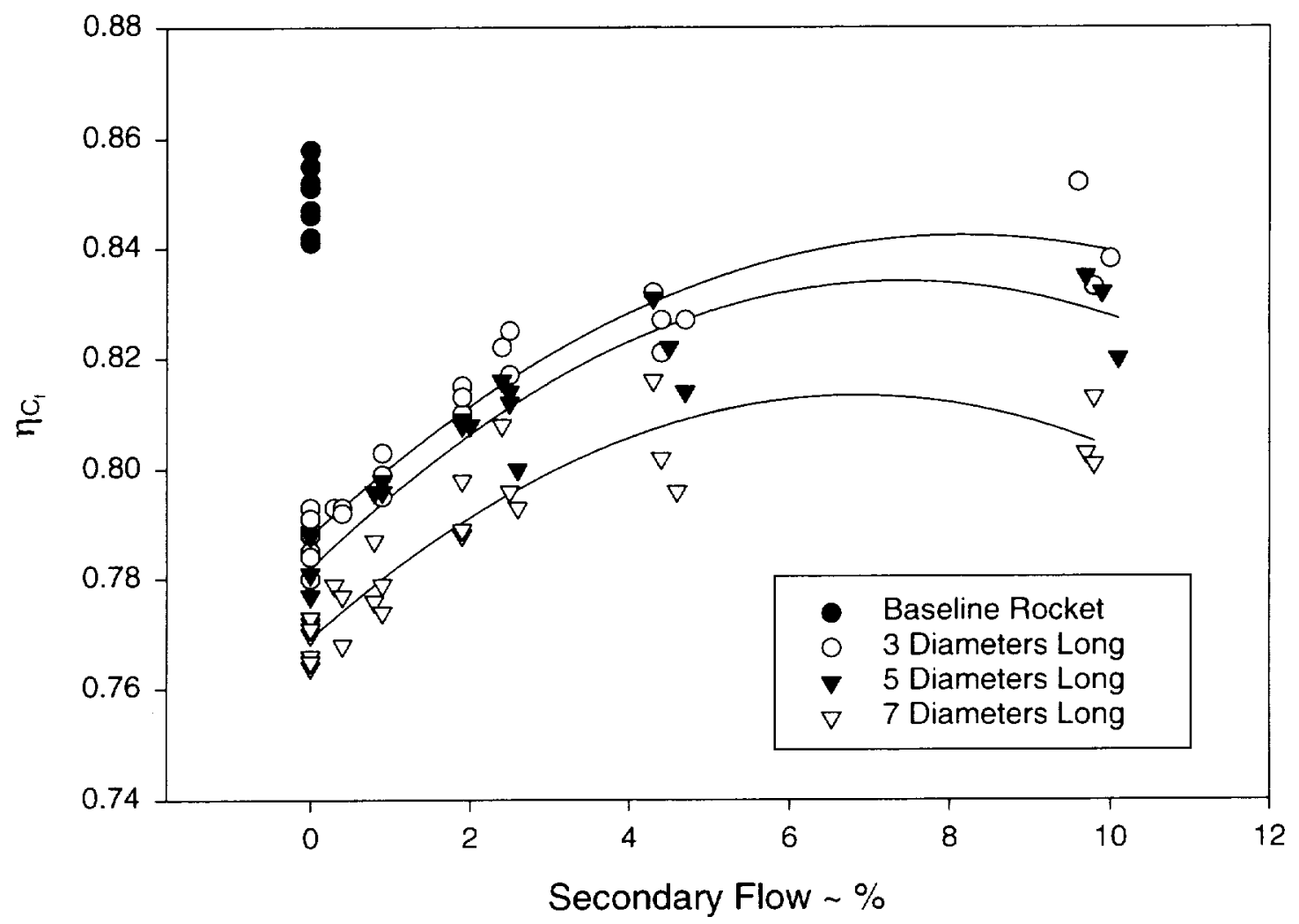

Figure 15. Thrust coefficient efficiency of rocket-in-a-duct with free expansion $\varepsilon=8-23.5$ as a function of percent secondary flow and length of duct 




Figure 16. Characteristic velocity efficiency of rocket-in-a-duct with free expansion $\varepsilon=8-23.5$ as a function of percent secondary flow and length of duct 



\section{REPORT DOCUMENTATION PAGE}

Public reporting burden for this collection of information is estimated to average 1 hour per response, including the time for reviewing instructions. searching existing data sources, gathering and maintaining the data needed, and compieting and reviewing the collection of intormation. Send comments regarding this burden estimate or any other aspect of this Davis Highway. Suite 1204. Arlinglon. VA 22202-4302. and to the Office of Management and Budget. Paperwork Reduction Project (0704-018B), Washington, DC 20503.
Darso

\begin{tabular}{|l|l|l|}
\hline 1. AGENCY USE ONLY (Leave blank) & $\begin{array}{r}\text { 2. REPORT DATE } \\
\text { October } 1999\end{array}$ & $\begin{array}{r}\text { R. REPORT TYPE AND DATES COVERED } \\
\text { Technical Memorandum }\end{array}$ \\
\hline
\end{tabular}

\section{TITLE AND SUBTITLE}

Rocket-in-a-Duct Performance Analysis
5. FUNDING NUMBERS

WU-242-72-01-00

Steven J. Schneider and Brian D. Reed

\section{PERFORMING ORGANIZATION NAME(S) AND ADDRESS(ES)}

National Aeronautics and Space Administration

John H. Glenn Research Center at Lewis Field

Cleveland, Ohio 44135-3191

\section{SPONSORING/MONITORING AGENCY NAME(S) AND ADDRESS(ES)}

National Aeronautics and Space Administration

Washington. DC 20546-0001
8. PERFORMING ORGANIZATION REPORT NUMBER

$\mathrm{E}-11918$
10. SPONSORING/MONITORING AGENCY REPORT NUMBER

NASA TM-1999-209440

AIAA 99-2101

11. SUPPLEMENTARY NOTES

Prepared for the 35th Joint Propulsion Conference and Exhibit cosponsored by the AIAA. ASME. SAE. and ASEE, Los Angeles, California. June 20-24. 1999. Responsible person, Steven J. Schneider, organization code 5430, (216) $977-7484$.

\section{2a. DISTRIBUTION/AVAILABILITY STATEMENT}

\section{2b. DISTRIBUTION CODE}

Unclassified - Unlimited

Subject Category: 20

Distribution: Nonstandard

This publication is available from the NASA Center for AeroSpace Information. (301) 621-0390.

13. ABSTRACT (Maximum 200 words)

An axisymmetric, $110 \mathrm{~N}$ class, rocket configured with a free expansion between the rocket nozzle and a surrounding duct was tested in an altitude simulation facility. The propellants were gaseous hydrogen and gaseous oxygen and the hardware consisted of a heat sink type copper rocket firing through copper ducts of various diameters and lengths. A secondary flow of nitrogen was introduced at the blind end of the duct to mix with the primary rocket mass flow in the duct. This flow was in the range of 0 to $10 \%$ of the primary massflow and its effect on nozzle performance was measured. The random measurement errors on thrust and massflow were within $+1-1 \%$. One dimensional equilibrium calculations were used to establish the possible theoretical performance of these rocket-in-a-duct nozzles. Although the scale of these tests was small, they simulated the relevant flow expansion physics at a modest experimental cost. Test results indicated that lower performance was obtained at higher free expansion area ratios and longer ducts, while, higher performance was obtained with the addition of secondary flow. There was a discernable peak in specific impulse efficiency at $4 \%$ secondary flow. The small scale of these tests resulted in low performance efficiencies, but prior numerical modeling of larger rocket-in-a-duct engines predicted performance that was comparable to that of optimized rocket nozzles. This remains to be proven in large-scale, rocket-in-a-duct tests.

\begin{tabular}{|c|c|c|c|}
\hline \multicolumn{3}{|c|}{$\begin{array}{l}\text { 14. SUBJECT TERMS } \\
\text { Rocket-based combined cycle; Rocket nozzle performance; Experimental data }\end{array}$} & \begin{tabular}{|c|} 
15. NUMBER OF PAGES \\
38 \\
16. PRICE CODE \\
AO 3 \\
\end{tabular} \\
\hline
\end{tabular}


. 
